\title{
Nanoporous Ag template from partially sintered Ag-Zn compact by dezincification
}

\author{
M MANDAL, A P MOON, S SANGAL and K MONDAL* \\ Department of Materials Science and Engineering, Indian Institute of Technology Kanpur, \\ Kanpur 208 016, India
}

MS received 22 November 2013

\begin{abstract}
A novel approach is followed to successfully fabricate nanoporous thin Ag template using partial sintering of elemental Ag and Zn (both have $99.9 \%$ purity) and subsequent dezincification. The starting materials for dezincification are partially sintered Ag-Zn aggregates (2.5, 5 and $10 \mathrm{wt} \% \mathrm{Zn})$. Partial sintering is done in order to achieve only interfacial bonding with the aim to maintain maximum potential difference between $\mathrm{Ag}$ and $\mathrm{Zn}$ particles during dezincification process in $1 \mathrm{~N} \mathrm{HCl}$ and $3.5 \mathrm{wt} \% \mathrm{NaCl}$ solutions. Two different dissolution methods, namely, simple immersion for 45 days and electrochemical way (holding the sample at critical potential), are employed. Electrochemical polarization tests are carried out to determine the critical potential for subsequent chrono-amperometry. X-ray diffraction, optical microscopy, scanning electron microscopy and energy dispersive $X$-ray spectroscopy are carried out to examine microstructural evolution, size, distribution and nature of pores in sintered aggregate as well as in template.
\end{abstract}

Keywords. Sintering; chrono-amperometry; porosity; dezincification; SEM; EDAX.

\section{Introduction}

Noble metals (Huang and Sun 2004; Yeh et al 2006; Jia et al 2007), such as $\mathrm{Au}, \mathrm{Ag}$, $\mathrm{Pt}$ and $\mathrm{Cu}$, are very useful in applications like separation membranes in fuel cells, fluid filters, electrodes, structural materials due to light weight, catalyst supports, heat exchangers, impact energy absorbers, adsorpants and flame arresters. This is because of their unique properties of very high surface area as well as suitable stiffness (Rintoul et al 1996; Bond and Thompson 1999; Joo et al 2001; Ding and Erlebacher 2003; Katagiri and Nakata 2003; You et al 2003). On the other hand, dealloying is a commonly noticed corrosion process in $\mathrm{Cu}-\mathrm{Zn}$ (Pickering and Wagner 1967), $\mathrm{Cu}-\mathrm{Au}$ (Fritz and Pickering 1991; Moffat et al 1991) and Ag-Au (Forty 1979; Erlebacher et al 2001), where selective chemical or electrochemical dissolution of a component of an alloy occurs even under normal atmospheric conditions. Fabrication of novel materials like $\mathrm{Au}$ ( $\mathrm{Li}$ and Sieradzki 1992), Cu (Hayes et al 2006), Ag (Qiu et al 2011), Ni (Pavlik and Adkins 1946), Ti (Wada et al 2011), Pt (Pugh et al 2005) and stainless steel (Chen and Sieradzki 2013) by dealloying has recently gained enormous attention due to their easy and effective processing route and ability to manipulate the final porous structure. On the other hand, different mechanisms of dezincifica-

*Author for correspondence (kallol@iitk.ac.in) tion have been proposed by various researchers (Deakin et al 2004) based on dissolution of active metal ions (Pickering and Wagner 1967), inter-diffusion (Pickering and Wagner 1967) and percolation theory (Sieradzki and Newman 1986; Newman et al 1988). Previous attempts on preparation of noble porous metallic sheets are concentrated on electro-deposition (Cherevko et al 2010), lyotropic liquid crystalline phases (Attard et al 1997; Bartlett et al 2002), foaming techniques using gas as blowing agent (Banhart 2001) and colloidal crystal templating (Velev and Kaler 2000). Several powder metallurgy techniques including loose powder sintering, slurry foaming and fibre metallurgy have also been tried for the production of high porosity metals (Shapovalov 1994). Even unidirectional solidification route under hydrogen gas has also been employed to achieve fine porous $\mathrm{Cu}$ (Nakajima et al 2001). But all these routes require extreme control, and are not easily available. Thus, dealloying route is found to be easy, yet successful route for fabrication of metals. So, fabrication of porous materials using sintering and dealloying route is quite a novel approach. Only disadvantage of this route is that the final amount of porosity is restricted to the amount of dissolution of the 2nd phase up to a certain limit decided by equilibrium phase diagram. Recently, Zhang et al (2012) have shown that melt-spun $\mathrm{Zn}-\mathrm{Ag}$ alloy ribbons of varied composition can form $\sim 50 \mu \mathrm{m}$ thick dealloyed Ag sheet in $\mathrm{NaCl}$ and $\mathrm{HCl}$ solutions. The idea of producing porous materials using dissolution route from partially sintered 
aggregates have never been tried previously. Recently, the present authors have made a successful attempt to make porous $\mathrm{Cu}$ template from partially sintered $\mathrm{Cu}-\mathrm{Zn}$ aggregate by dealloying (dezincification) after immersion in $\mathrm{NaCl}$ and $\mathrm{HCl}$ solutions (Mandal et al 2013). Further, this route does not provide any complicacy as it only involves simple powder mixing using ball milling, partial sintering and electrochemical studies (simple immersion or chrono-amperometry). Similar novel approach (mechanical mixing of pure Ag and Zn powders in ball mill, partial pressureless sintering, dealloying by immersion as well by chrono-amperometry) has been followed in the present work for the first time to successfully produce Ag template. Potentiodynamic polarization and chronoamperometry studies have been performed further to modify the final microstructure of Ag template.

\section{Experimental}

According to the Ag-Zn binary phase diagram (shown in figure 1 (Massalski 1986)) and considering the solid solution range of $\mathrm{Ag}$ and $\mathrm{Zn}$, three compositions were chosen, such that vigorous formation of intermetallic compounds might be avoided at room temperature as well as at elevated temperature. Electrolytically prepared Zn powder (99.9\% pure, density $7.13 \mathrm{~g} / \mathrm{cm}^{3}$ ) and Ag powder (99.5\% pure, density $10.46 \mathrm{~g} / \mathrm{cm}^{3}$ ) were then milled in a planetary ball mill (Fritsch Planetary Ball Mill, Pulverisette 5 PM400) at $200 \mathrm{rpm}$ for $45 \mathrm{~min}$ to prepare three sets of powders having compositions Ag-2.5 wt\% Zn, Ag$5 \mathrm{wt} \% \mathrm{Zn}$ and Ag-10 wt\% Zn. Milling was carried out using tungsten carbide vials and tungsten carbide balls of $10 \mathrm{~mm}$ diameter in a dry atmosphere with a ball to powder ratio of $10: 1$. Compaction had, then, been done for each of the samples using $10 \mathrm{~mm}$ stainless-steel die for $15 \mathrm{~s}$

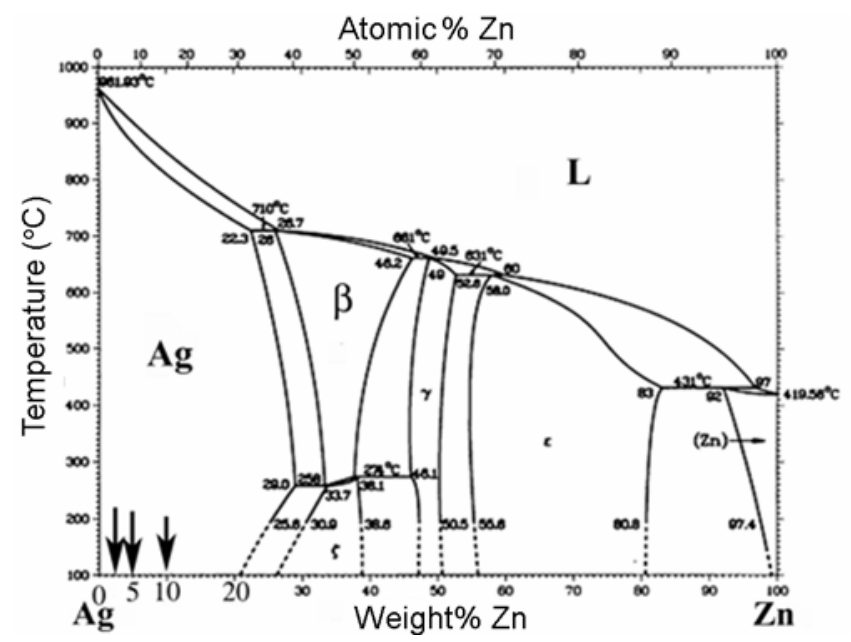

Figure 1. Binary alloy phase diagram of Ag-Zn (Yeh et al 2006) and the position of the chosen Ag-Zn mixtures is shown in the figure with arrowhead. under uni-axial load of $4.5 \mathrm{kN}$. The green densities of the compacts were then measured, and relative densities with respect to the theoretical density were assessed. Sintering was then done in low vacuum $\left(10^{-2} \mathrm{mbar}\right)$ at two different temperatures of 450 and $500{ }^{\circ} \mathrm{C}$ for 15 min to restrict oxidation of Ag. The samples were then furnace cooled up to $150{ }^{\circ} \mathrm{C}$ followed by air cooling to room temperature. X-ray diffraction (XRD) using $\mathrm{CuK} \alpha$ radiation $(\lambda=0 \cdot 15418 \mathrm{~nm})$ was carried out after ball milling and sintering. The peaks were compared with the standard peaks using PCPDFWIN and X'pert Highscore plus software. Density of the sintered pellets was measured by the Archimedes method following ASTM B962-08 standard. The pellets were first weighed in air using a weighing balance cum density kit (Mettler Toledo), and then, they were soaked with oil to close the open pores on the surface. The soaked samples were weighed inside water. Direct density values were obtained from the machine. Following formula was used for the calculation of sinterability of the pellets:

Sinterability = experimental density/theoretical density.

Scanning electron microscopy (SEM) (Model SEM ZEISS EVO 50) was carried out for micro-structural characterization of the sintered samples. Metallographic samples were prepared by polishing on 400-2000 grit $\mathrm{SiC}$ paper, followed by cloth polishing using $5 \mu \mathrm{m}$ alumina. SEM equipped with energy dispersive X-ray spectrometer (EDS) was used for compositional analysis (point as well as elemental mapping) to study the degree of uniformity and distributions of the different constituents in sintered samples. Bulk hardness was measured using the Vickers indenter by applying a load of $50 \mathrm{~g}$ for $10 \mathrm{~s}$, and minimum 20 indentations were recorded for each sample at random places in order to have a representative average value of hardness.

For dezincification studies, $0.5 \mathrm{~mm}$ thick discs were sliced out from sintered pellets of $10 \mathrm{~mm}$ diameter. Direct immersion tests were carried out on Ag-Zn samples sintered at $500{ }^{\circ} \mathrm{C}$ by suspending each of the fine-polished pellet samples (up to 1600 grit size) in separate conical flasks containing $250 \mathrm{~mL}$ of two different types of nonagitated solutions $1 \mathrm{M} \mathrm{HCl}(\mathrm{pH} 0.47)$ and $3.5 \mathrm{wt} \% \mathrm{NaCl}$ $(\mathrm{pH} 7 \cdot 2)$ for 45 days maintained at room temperature $\left(25^{\circ} \mathrm{C}\right)$. The samples were then properly cleaned ultrasonically in acetone for $10 \mathrm{~min}$. Microstructural analysis was then performed in SEM equipped with EDS for the characterization of size, distribution and nature of pores after dezincification.

Electrochemical studies, including open-circuit polarization (OCP) measurements, potentiodynamic polarization and finally chrono-amperometry, were carried out in conventional electrochemical flat bottom cell using a potentiostat (Model 2263, Princeton Applied Research, USA) at room temperature in an open ambient condition. Platinum gauze was used as the counter electrode. The electrode potential was measured using a saturated calomel 
electrode (SCE) as reference electrode $\left(E_{\mathrm{SCE}}=241 \mathrm{mV}\right)$. The Ag-Zn pellets were directly used as working electrode. The electrolytes used were freshly prepared $1 \mathrm{M}$ $\mathrm{HCl}(\mathrm{pH} 0.49)$ and $3.5 \mathrm{wt} \% \mathrm{NaCl}(\mathrm{pH} 7 \cdot 2)$. In order to avoid experimental errors, OCP and potentiodynamic measurements were repeated at least two times. For the potentiodynamic polarization measurements, the scanning rate was chosen to be $0.75 \mathrm{mV} / \mathrm{s}$. The critical potentials for chrono-amperometry were chosen from the potentiodynamic studies of the partially sintered samples for fabrication of porous Ag pellets. The samples after chrono-amperometry were then properly cleaned ultrasonically in acetone for $10 \mathrm{~min}$. Microstructural analysis was then performed in SEM equipped with EDS for the characterization of size, distribution and nature of pores after dezincification.

\section{Results and discussion}

Figure 2(a) and (b) shows the XRD patterns of pure Ag and $\mathrm{Zn}$ powders and the mixed Ag-Zn powders after ball milling, respectively. The ball-milled powders show distinct Ag peaks, whereas the $\mathrm{Zn}$ peaks are relatively weaker because only $2 \cdot 5,5$ and $10 \mathrm{wt} \% \mathrm{Zn}$ are present. The presence of distinct Ag and $\mathrm{Zn}$ peaks in the ballmilled powders shows that predominantly Ag and $\mathrm{Zn}$ are present in elemental form in the milled powders. However, the patterns show some additional peaks confirming the formation of small fraction of AgZn (cubic), $\mathrm{Ag}_{5} \mathrm{Zn}_{8}$, $\mathrm{AgZn}_{3}$ and $\mathrm{AgZn}$ (hexagonal) phases. This suggests that there is a possibility of reaction between $\mathrm{Zn}$ and $\mathrm{Ag}$ particles at the powder particle interfaces during low-energy ball milling.
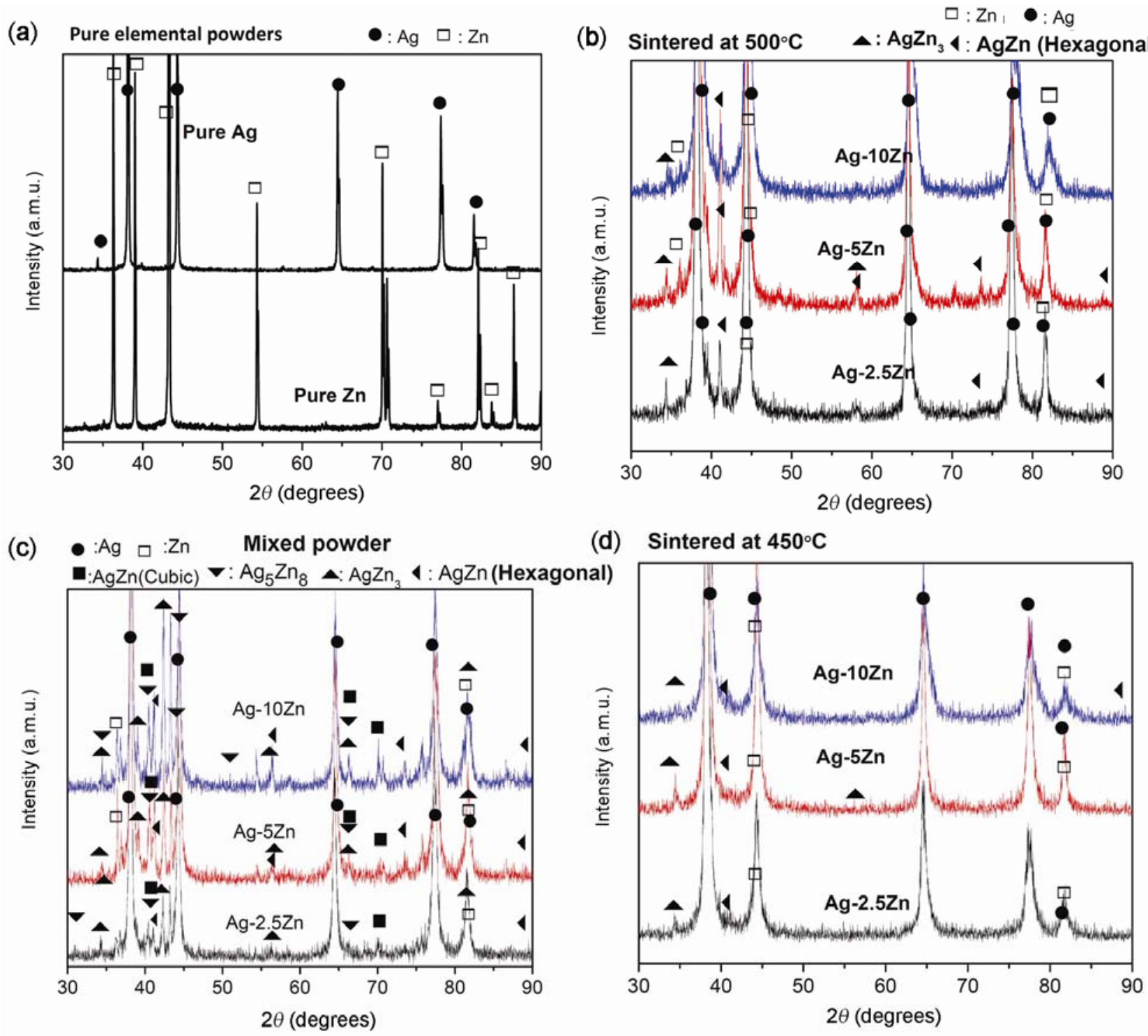

Figure 2. X-ray diffraction patterns of (a) pure Ag and $\mathrm{Zn}$ elemental powders and (b) ball-milled powders, sintered Ag-2.5 wt $\%$ Zn, Ag-5 wt\% Zn and Ag-10 wt\% Zn at (c) $500{ }^{\circ} \mathrm{C}$ and (d) $450{ }^{\circ} \mathrm{C}$. 
Figure 2(c) and (d) shows the XRD patterns from the sintered Ag-Zn aggregates at 500 and $450{ }^{\circ} \mathrm{C}$, respectively. These patterns clearly show that with increase in Zn content as well as with increase in sintering temperature, new peaks appear apart from the elemental peaks. However, elemental peaks of pure $\mathrm{Zn}$ and Ag still persist suggesting that there are reactions between Ag and $\mathrm{Zn}$ at the particle boundaries. Formation of intermetallics like $\mathrm{AgZn}_{3}, \mathrm{Ag}_{5} \mathrm{Zn}_{8}$ (cubic), AgZn (cubic) and AgZn (hexagonal) occurs in the sintered samples too.
Figure 3(a) shows the variation of green densities of the compacted samples and that of the sintered pellets as a function of $\mathrm{Zn}$ content. The density increases with decrease in $\mathrm{Zn}$ content, suggesting better sintering, although the rate of change in density is almost constant. Figure 3(b) shows the corresponding plot of variation of sinterability as a function of Zn content. The density of the sintered sample is maximum $\left(9.04 \mathrm{~g} / \mathrm{cm}^{3}\right)$ at the highest sintering temperature $\left(500^{\circ} \mathrm{C}\right)$ and minimum $\mathrm{Zn}$ content $(2.5 \mathrm{wt} \%)$. On the other hand, density is minimum
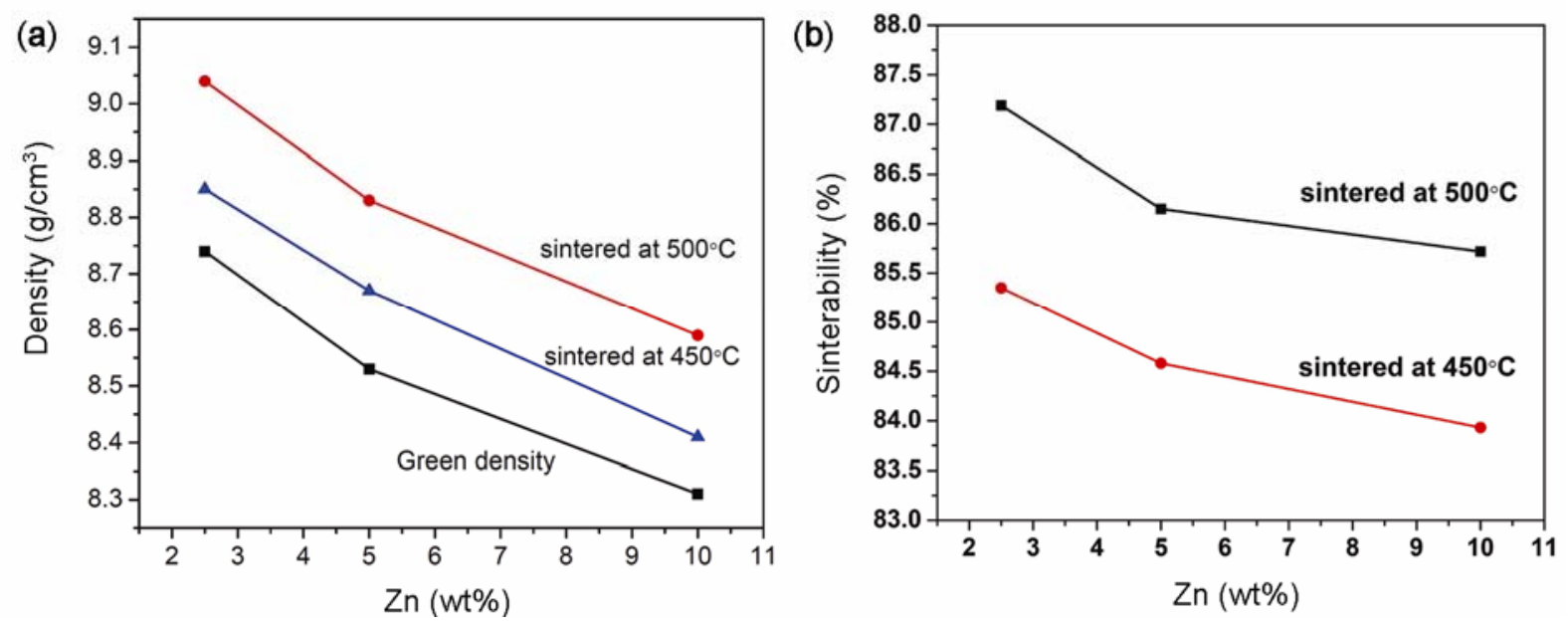

Figure 3. Variation of (a) density and (b) sinterability of the green compact and sintered pellets as a function of composition.
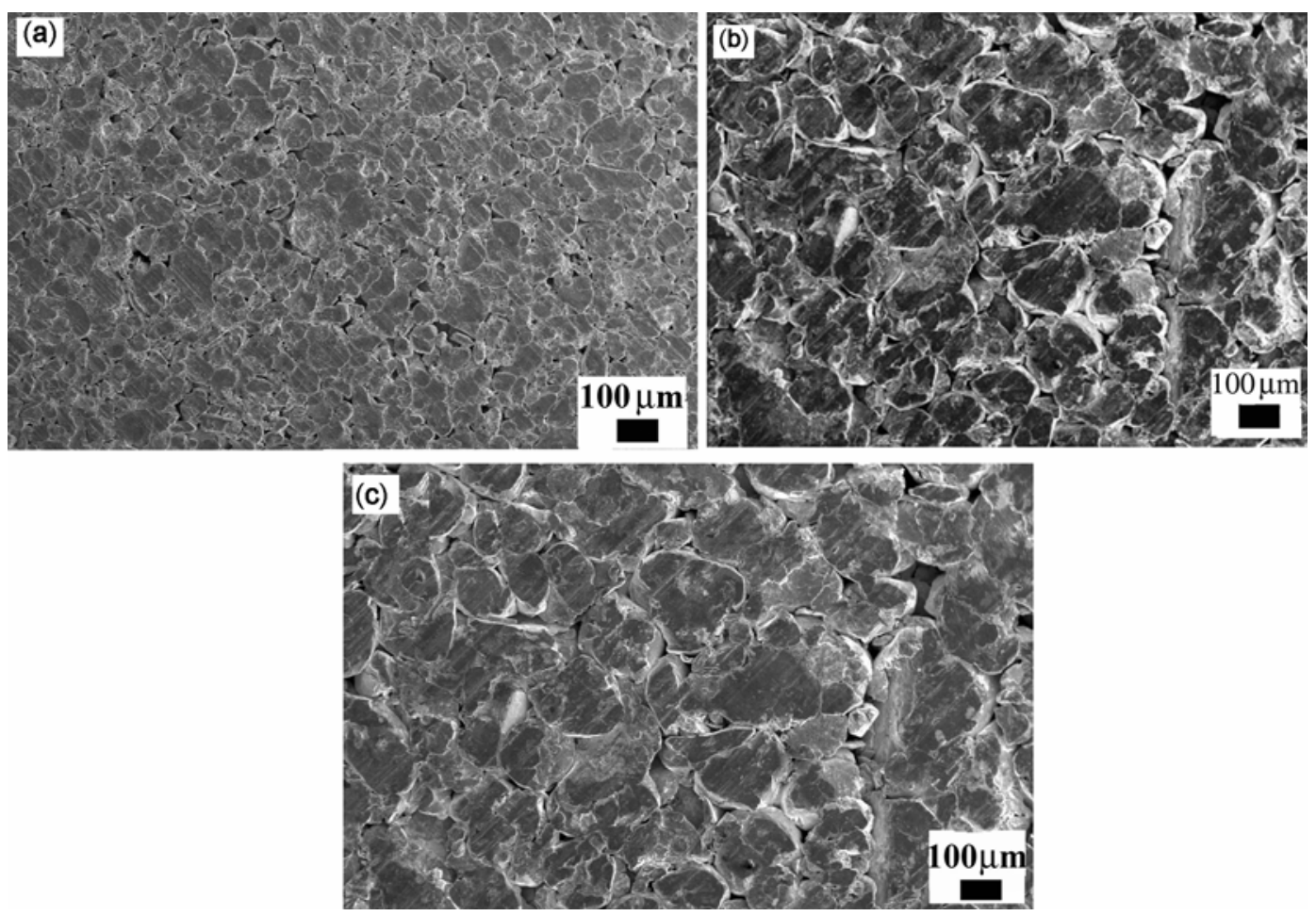

Figure 4. Scanning electron micrographs of (a) Ag-2.5 wt\% Zn, (b) Ag-5 wt\% Zn and (c) Ag-10 wt\% $\mathrm{Zn}$ samples sintered at $450{ }^{\circ} \mathrm{C}$. 
$\left(8.41 \mathrm{~g} / \mathrm{cm}^{3}\right)$ at $450{ }^{\circ} \mathrm{C}$ with maximum $\mathrm{Zn}$ content $(10 \mathrm{wt} \%)$. This is due to the fact that the density of elemental $\mathrm{Zn}\left(7 \cdot 14 \mathrm{~g} / \mathrm{cm}^{3}\right)$ is much lower than that of $\mathrm{Ag}$ $\left(10.49 \mathrm{~g} / \mathrm{cm}^{3}\right)$, and upon mixing, the density decreases due to the presence of low-density $\mathrm{Zn}$. Moreover, $\mathrm{Zn}$ might have evaporated also during sintering, leading to porosity.

Figure 4(a)-(c) shows the scanning electron micrographs in the secondary electron imaging mode (SE) of Ag-2.5 wt\% Zn, Ag-5 wt\% Zn and Ag-10 wt\% Zn, sintered at $450{ }^{\circ} \mathrm{C}$, respectively. The dark phases indicate the presence of Ag-rich phases, while the bright phases indicate $\mathrm{Zn}$-rich phases. $\mathrm{Zn}$ is distributed throughout the matrix in the interface regions of Ag particles in all the samples. With increasing Zn content, the Ag-rich regions tend to increase in size. Very-fine microstructure is observed in Ag-2.5 wt\% Zn sintered at $450{ }^{\circ} \mathrm{C}$. Coarsegrained microstructure is found in case of Ag-10 wt\% Zn. This could be associated with composition-assisted grain boundary migration of Ag grain in contact with $\mathrm{Zn}$ (Balluffi and Cahn 1981). However, the present paper presents more on dealloying and associated porous structure. From EDS area mapping, the volume fraction of
Zn-rich phase is found to be $2 \cdot 04 \%, 4 \cdot 29 \%$ and $9 \cdot 1 \%$ in cases of Ag-2.5 wt\% Zn, Ag-5 wt\% Zn and Ag-10 wt\% $\mathrm{Zn}$, respectively. The remaining $\mathrm{Zn}$ could have evaporated during sintering. However, near about $90 \% \mathrm{Zn}$ is retained in each aggregate irrespective of composition after sintering. There could be loss of Zn during milling also. Figure 5 shows the elemental mapping of zinc and silver carried out on Ag-10 wt\% Zn sintered at $450{ }^{\circ} \mathrm{C}$. The EDS superimposition on the original microstructure shows Agrich and Zn-rich regions clearly. The elemental mapping showing distribution of Ag-rich and Zn-rich phases in Ag$10 \mathrm{wt} \% \mathrm{Zn}$ after sintering at $500{ }^{\circ} \mathrm{C}$ are shown in figure 6 . The large grains are mostly in Ag-rich regions, whereas $\mathrm{Zn}$ is found to be present mostly in grain boundary regions.

Figure 7(a) and (b) shows the plots describing the variation of the Vickers hardness with increase in Zn content and sintering temperatures, respectively. The Vickers hardness shows an increasing tendency with decreasing $\mathrm{Zn}$ content as well as increasing sintering temperature, and it is highest (97.4 VHN) for Ag-2.5 wt\% Zn sample sintered at the highest sintering temperature $\left(500{ }^{\circ} \mathrm{C}\right)$. It is also noticed that the hardness of $\mathrm{Zn}$-rich regions is much lower than Ag-rich regions. It is due to increase in $\mathrm{Zn}$

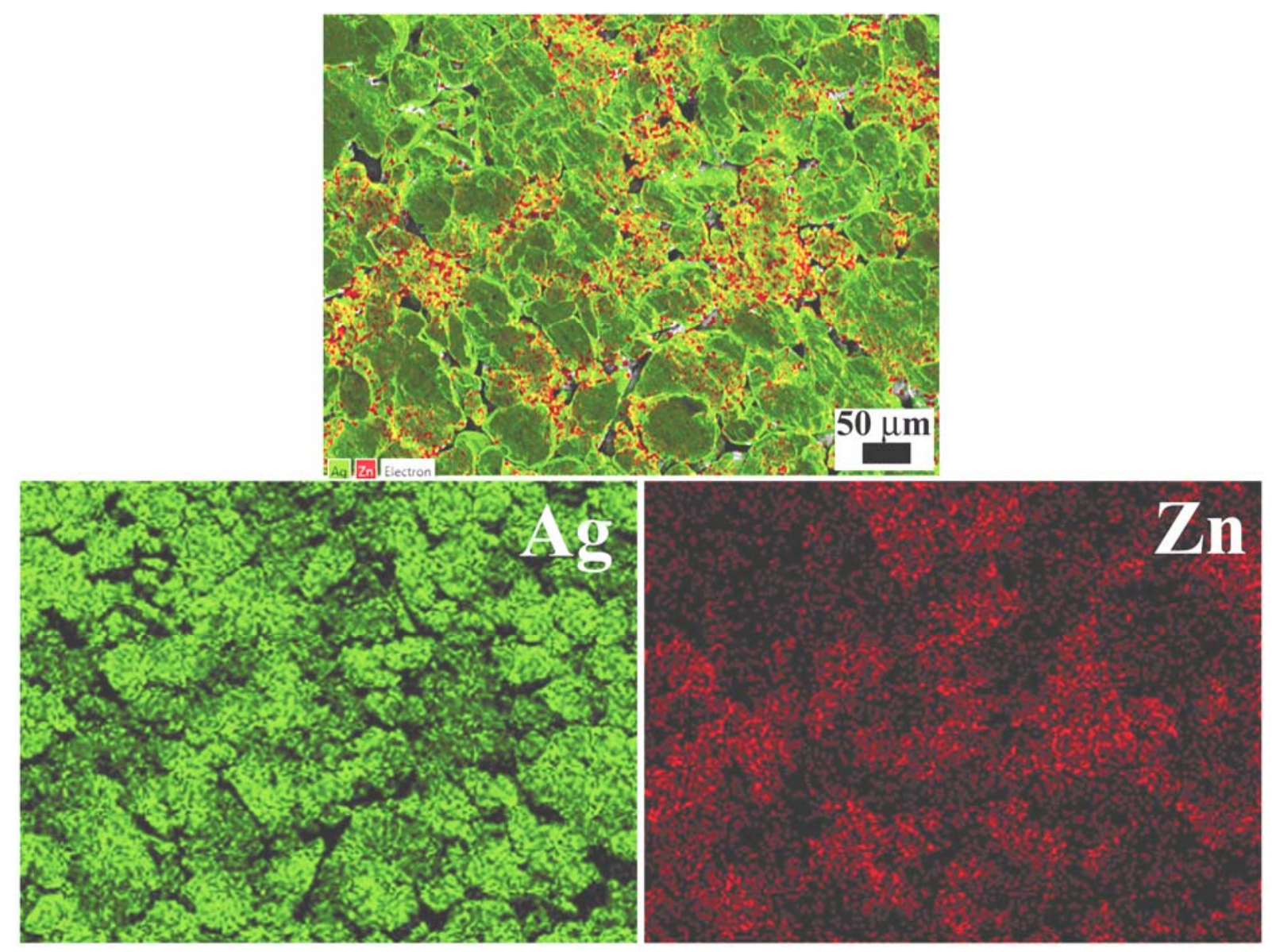

Figure 5. Elemental mapping showing distribution of Ag-rich and Zn-rich phases in the Ag-10 wt\% Zn sample sintered at $450{ }^{\circ} \mathrm{C}$. 


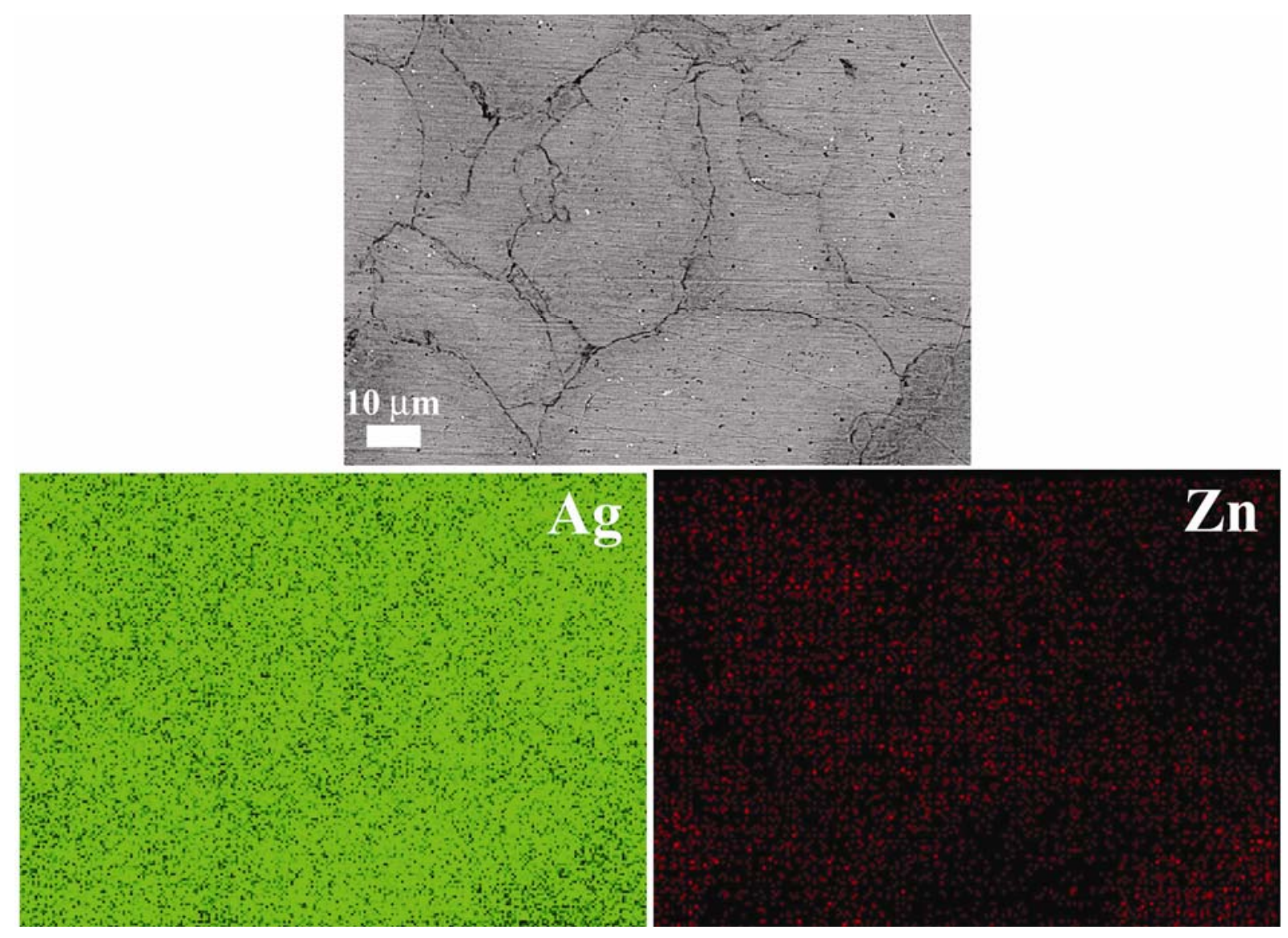

Figure 6. Elemental mapping showing distribution of Ag-rich and Zn-rich phases in the Ag-10 wt\% Zn sample sintered at $500{ }^{\circ} \mathrm{C}$.

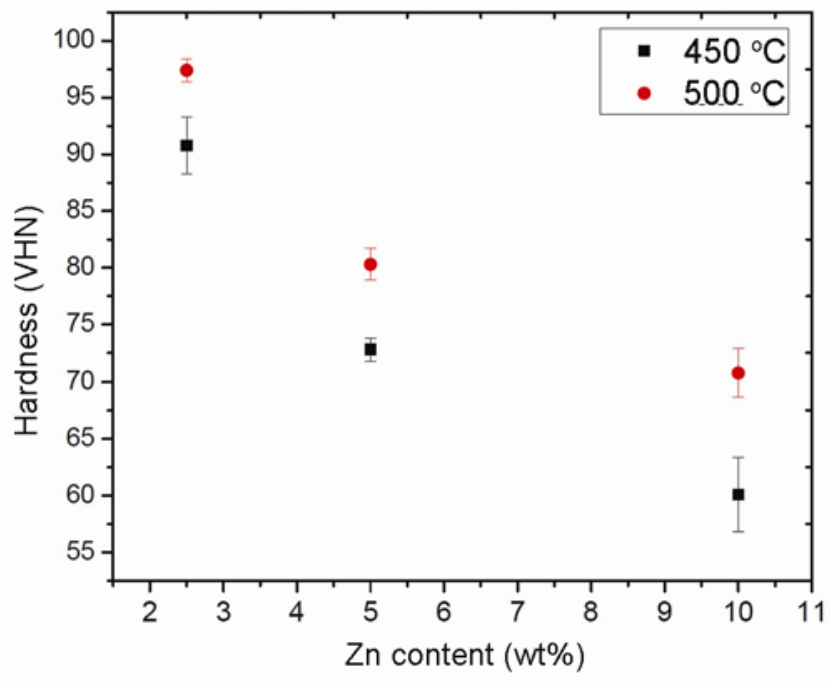

Figure 7. Variation in bulk hardness (Vickers) with respect to Zn content in sintered Ag-Zn samples.

content, and there is a sharp decline in the hardness of the samples. With an increase in sintering temperature, better interparticle bonding occurs leading to a higher hardness value.
Scanning electron micrographs (figure $8 \mathrm{a}$ and $\mathrm{b}$ ) show morphology of the surface of Ag-10 wt\% Zn sintered at $500{ }^{\circ} \mathrm{C}$ after immersion in $3 \cdot 5 \% \mathrm{NaCl}$ and $1 \mathrm{M} \mathrm{HCl}$, respectively, for 45 days. EDS analysis has been performed at several points in order to obtain the amount of $\mathrm{Ag}$ and $\mathrm{Zn}$. Table 1 shows the data of EDS analysis marked by points A, B and C as shown in figure 8(a) and (b). Very fine pores ranging from $200 \mathrm{~nm}$ to $1 \mathrm{~mm}$ have formed in the Ag-10 wt\% $\mathrm{Zn}$ sintered at $500{ }^{\circ} \mathrm{C}$ sample after dissolution in $1 \mathrm{M} \mathrm{HCl}$ sample (figure $8 \mathrm{~b}$ ). But, the morphology after dissolution in $3.5 \% \mathrm{NaCl}$ seems to be somewhat different (figure 8a), showing inhomogeneous distribution of large and fine sized pores. The EDS data further shows that oxide content is very low in all the samples even after dissolution in aerated solution, and the dissolution of $\mathrm{Zn}$ is quite pronounced in both $\mathrm{HCl}$ and $\mathrm{NaCl}$ solutions (table 1). Scanning electron micrographs (figure 8c and d) show the morphology of the surface of the $\mathrm{Ag}-5 \mathrm{wt} \% \mathrm{Zn}$ sintered at $500{ }^{\circ} \mathrm{C}$ after immersion in $3 \cdot 5 \% \mathrm{NaCl}$ and $1 \mathrm{M} \mathrm{HCl}$, respectively, for 45 days. The EDS analysis at the points marked in figure 8(c) and (d) is presented in table 1 . In case of the Ag-5 wt\% $\mathrm{Zn}$ sample immersed in $3.5 \% \mathrm{NaCl}$, the range of pore size reduces, and homogeneous porous microstructure is 

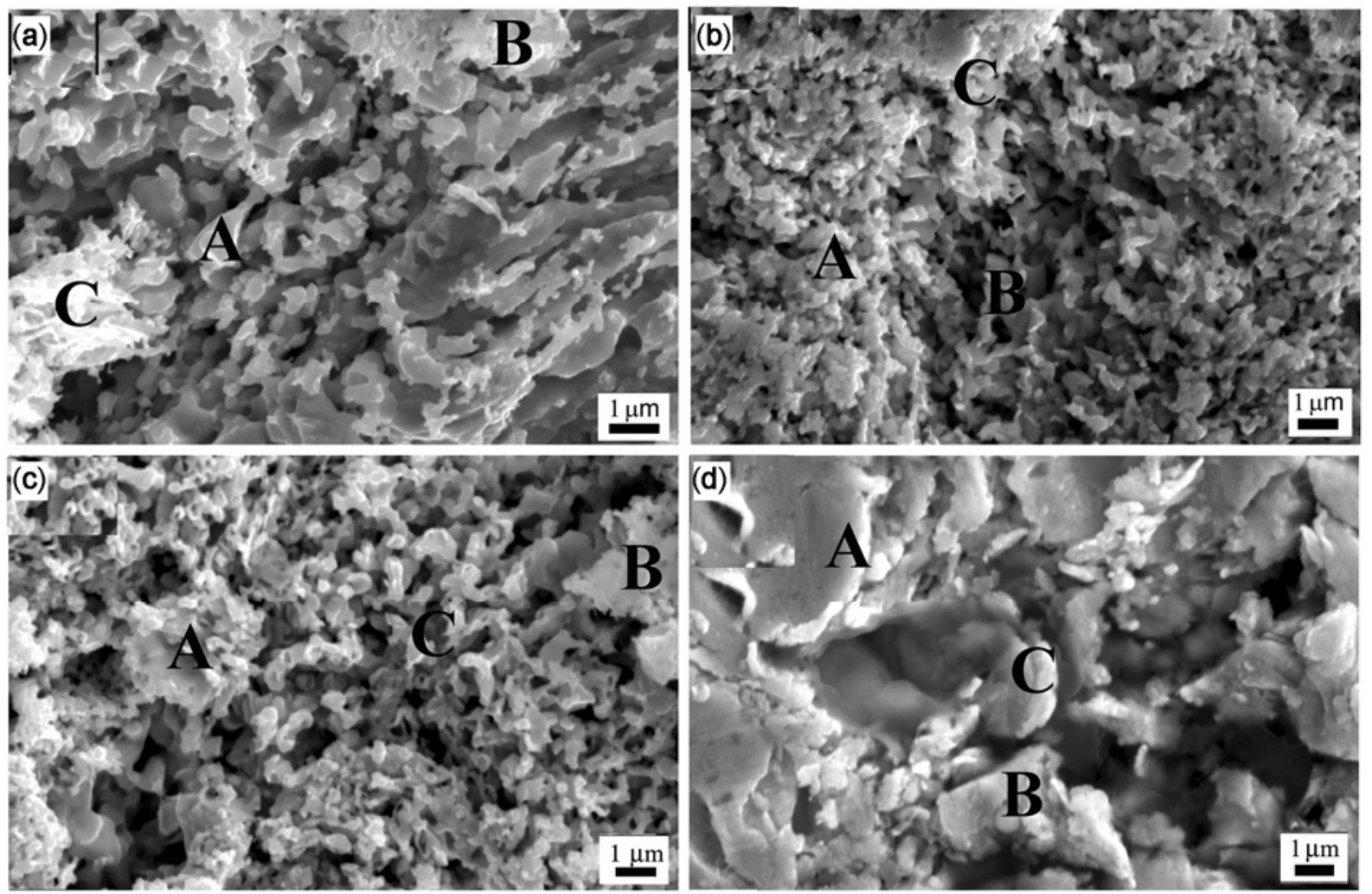

Figure 8. Scanning electron micrographs of the Ag-10 wt\% Zn sample sintered at $500{ }^{\circ} \mathrm{C}$ after immersion (a) in $3 \cdot 5 \%$ $\mathrm{NaCl}$ and (b) in $1 \mathrm{M} \mathrm{HCl}$ for 45 days; and scanning electron micrographs of $\mathrm{Ag}-5 \mathrm{wt} \% \mathrm{Zn}$ sample sintered at $500{ }^{\circ} \mathrm{C}$ after immersion (c) in $3.5 \% \mathrm{NaCl}$ and (d) in $1 \mathrm{M} \mathrm{HCl}$ for 45 days.

Table 1. Compositional analysis (EDS) at the points marked in the micrographs of the corroded surfaces of Ag-Zn samples sintered at $500{ }^{\circ} \mathrm{C}$ after immersion as shown in figure 8 .

\begin{tabular}{|c|c|c|c|c|c|c|}
\hline Composition & Corrosive used & $\begin{array}{l}\text { Location of } \\
\text { EDS spectrum }\end{array}$ & $\mathrm{Ag}(\mathrm{wt} \%)$ & $\mathrm{Zn}(\mathrm{wt} \%)$ & $\mathrm{O}(\mathrm{wt} \%)$ & Avg. pore size \\
\hline \multirow[t]{6}{*}{ Ag-10 wt $\%$ Zn } & $1 \mathrm{M} \mathrm{HCl}$ (figure 8b) & A & $97 \cdot 15$ & 0 & $2 \cdot 85$ & $560 \mathrm{~nm}$ \\
\hline & & B & $94 \cdot 80$ & $4 \cdot 16$ & 1.04 & \\
\hline & & $\mathrm{C}$ & $92 \cdot 54$ & $6 \cdot 49$ & $0 \cdot 97$ & \\
\hline & 3.5\% NaCl (figure 8a) & A & $97 \cdot 63$ & $2 \cdot 21$ & $0 \cdot 16$ & $620 \mathrm{~nm}$ \\
\hline & & B & $93 \cdot 22$ & $6 \cdot 41$ & $0 \cdot 37$ & \\
\hline & & $\mathrm{C}$ & $94 \cdot 59$ & $5 \cdot 28$ & $0 \cdot 13$ & \\
\hline \multirow[t]{6}{*}{ Ag-5 wt\% Zn } & $1 \mathrm{M} \mathrm{HCl}$ (figure 8d) & A & $96 \cdot 26$ & $3 \cdot 54$ & $0 \cdot 20$ & $4.2 \mu \mathrm{m}$ \\
\hline & & B & $95 \cdot 62$ & $3 \cdot 16$ & $1 \cdot 22$ & \\
\hline & & $\mathrm{C}$ & $95 \cdot 29$ & $3 \cdot 87$ & $0 \cdot 84$ & \\
\hline & 3.5\% NaCl (figure 8c) & A & $95 \cdot 30$ & $4 \cdot 70$ & 0 & $1.8 \mu \mathrm{m}$ \\
\hline & & B & $96 \cdot 11$ & $3 \cdot 15$ & $0 \cdot 74$ & \\
\hline & & $\mathrm{C}$ & $95 \cdot 44$ & $4 \cdot 17$ & $0 \cdot 39$ & \\
\hline
\end{tabular}

observed with pore size varying from 200 to $500 \mathrm{~nm}$ (figure 8c). As compared to the Ag-10 wt\% Zn samples, the dissolution of $\mathrm{Zn}$ is not that pronounced. Almost full $\mathrm{Zn}$ (5 wt\%) with respect to the original sintered sample is retained at all the points. This may lead to the conclusion that selective dissolution of $\mathrm{Zn}$ has not occurred, and instead of that, overall dissolution from both Zn-rich and Ag-rich phases has taken place. But, in both the samples, oxide film is not present even after dissolution in aerated solutions, and it may be due to the noble nature of $\mathrm{Ag}$. Figure 9(a) and (b) shows the elemental mapping of zinc and silver carried out on $\mathrm{Ag}-10 \mathrm{wt} \% \mathrm{Zn}$ sintered at $500{ }^{\circ} \mathrm{C}$ after immersion test for 45 days in $1 \mathrm{M} \mathrm{HCl} \mathrm{solu-}$ tion and $3.5 \% \mathrm{NaCl}$ solution, respectively. Predominantly $\mathrm{Ag}$ is present, and the presence of little $\mathrm{Zn}$ is overshadowed by the Ag signals. 

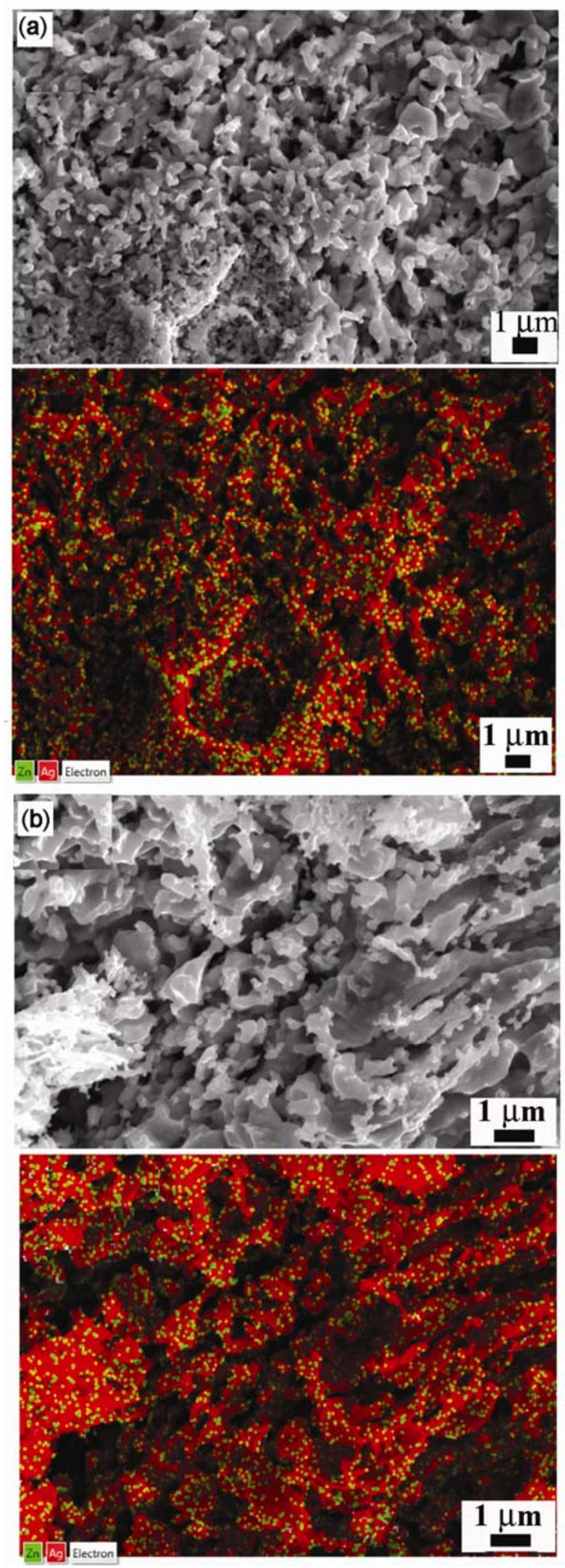

Figure 9. Mapping of the overall corroded surface area showing elemental distribution of $\mathrm{Ag}$ and $\mathrm{Zn}$ in the $\mathrm{Ag}-10 \mathrm{wt} \% \mathrm{Zn}$ sample sintered at $500{ }^{\circ} \mathrm{C}$ and immersed in (a) $1 \mathrm{M} \mathrm{HCl}$ and (b) $3.5 \% \mathrm{NaCl}$ for 45 days.
Since the chemical response, i.e. evolution of pores is quite pronounced in immersion tests, there is a possibility that better results, i.e. homogeneous nanopores may be obtained on performing electrochemical experiments. The main idea behind this objective is that if the sample surface is exposed to the electrolyte at a stipulated potential, such that the potential is quite higher than the stability range of $\mathrm{Zn}$, then controlled porosity can be obtained and the pore size can also be manipulated. Potentiodynamic polarization tests have thus been conducted to determine the critical potential and finally, chrono-amperometric studies have been conducted to obtain the final porous structure.

Figure 10(a) and (b) shows the potential vs pH (Pourbaix diagram) of $\mathrm{Ag}$ and $\mathrm{Zn}$ system, drawn to the same scale, respectively (Pourbaix 1966). Comparing the range of stability of elemental Ag (standard electrode potential 0.799 ) and $\mathrm{Zn}$ (standard electrode potential 0.762), it can be considered that elemental $\mathrm{Ag}$ is retained in the electrolyte even at much higher voltages than that of $\mathrm{Zn}$. Thus, it can be assumed that the re-deposition of Ag takes place at a much lower potential than $\mathrm{Zn}$, whereas selective
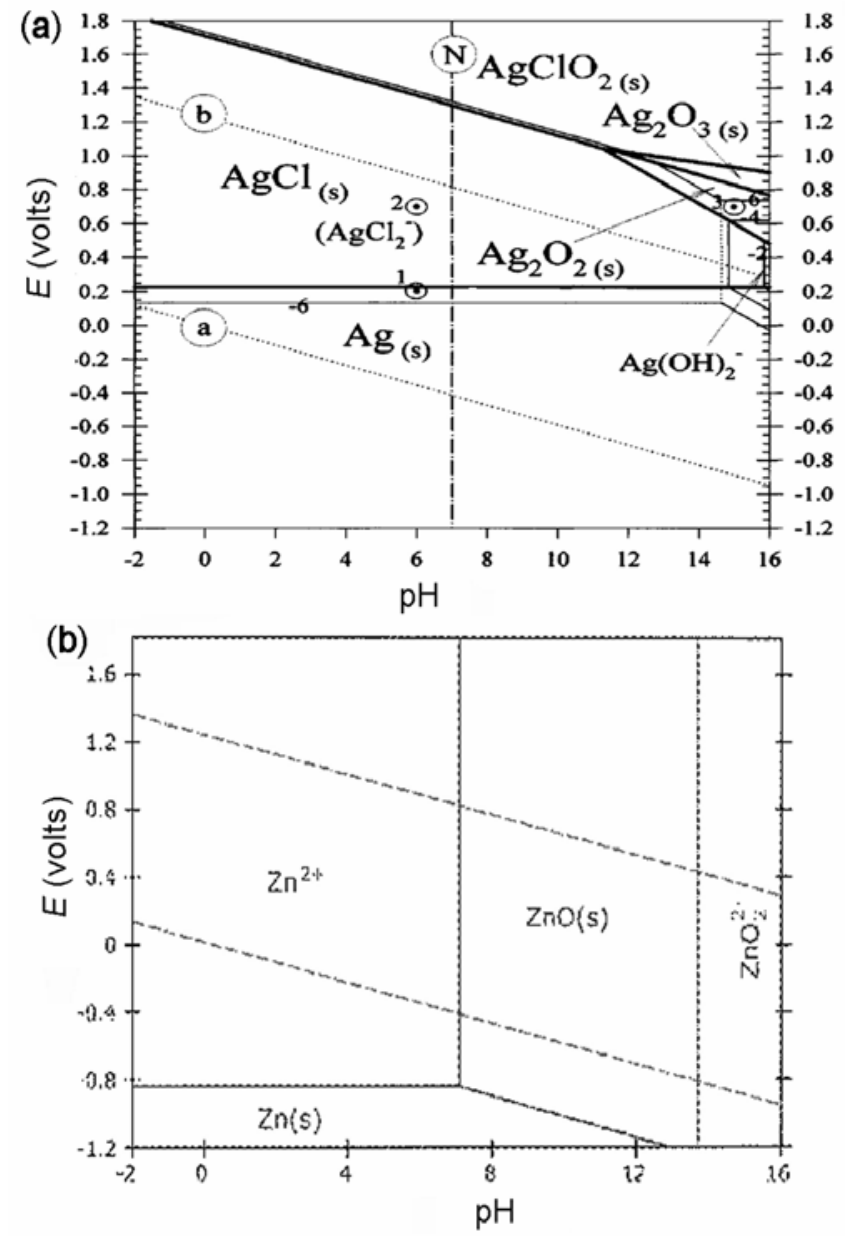

Figure 10. $E-\mathrm{pH}$ diagram of (a) Ag and (b) Zn drawn to same scale (You et al 2003). 
dissolution of $\mathrm{Zn}$ is inevitable at higher potentials up to 0.799 V. The Pourbaix diagram further explains that $\mathrm{pH}$ of the electrolyte is very important since at higher $\mathrm{pH}$, the stability of $\mathrm{Zn}$ further decreases and oxidation of $\mathrm{Zn}$ is likely to occur instead of selective dissolution. For this reason, low $\mathrm{pH}$ solution $(1 \mathrm{M} \mathrm{HCl}$ in the present case) and neutral solution $(3.5 \% \mathrm{NaCl})$ are chosen for performing the dissolution studies. The potentiodynamic polarization studies were conducted after stabilizing the open circuit potential (OCP) of the prematurely sintered Ag-Zn aggregates in $1 \mathrm{M} \mathrm{HCl}$ and $3 \cdot 5 \% \mathrm{NaCl}$ for $60 \mathrm{~min}$.

The corresponding potentiodynamic polarization plots of the Ag-Zn aggregates are shown in figure 11(a) and (b) in $1 \mathrm{M} \mathrm{HCl}$ and $3.5 \% \mathrm{NaCl}$, respectively. Critical potentials between the onset of transpassive and the passive zones on the anodic region are chosen for the corresponding samples, so as to facilitate further potentiostatic polarization studies at that critical potential, which may result into controlled porous structure. Table 2 shows all the critical potentials for all the samples.

Figure 12(a) and (b) shows the chrono-amperometric curves of the sintered Ag-Zn aggregates held at corresponding critical potentials in $3 \cdot 5 \% \mathrm{NaCl}$ and $1 \mathrm{M} \mathrm{HCl}$, respectively. Dealloying has occurred from a circular area of $6 \mathrm{~mm}$ diameter. Critical potentials (shown in table 2) are chosen from the corresponding potentiodynamic polarization plots and the samples are held at that potential for $3600 \mathrm{~s}$. The corresponding changes in current density

\section{In $1 \mathrm{M} \mathrm{HCl}$}

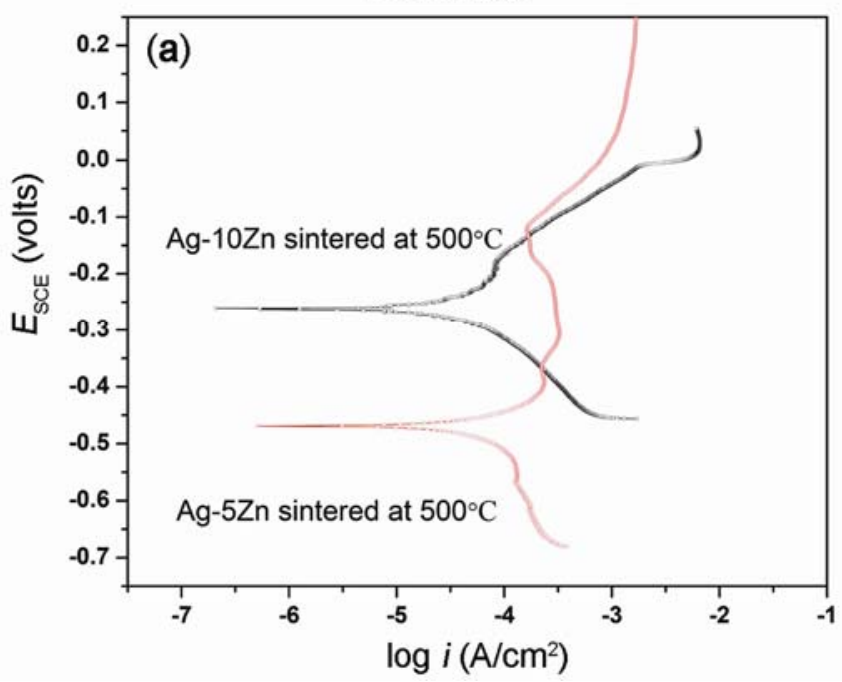

In $3.5 \% \mathrm{NaCl}$

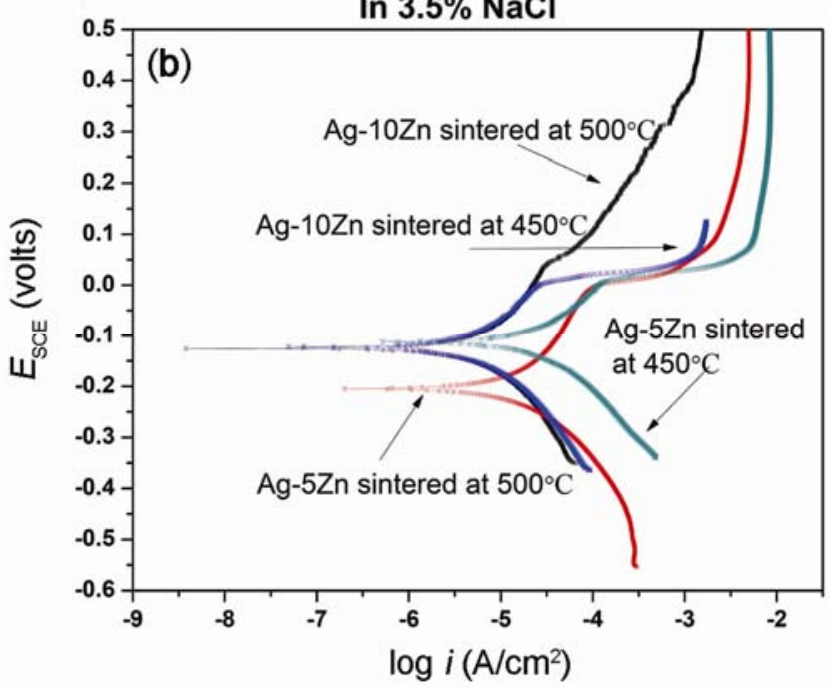

Figure 11. Potentiodynamic polarization (Tafel plot) of sintered Ag-Zn samples in (a) $1 \mathrm{M} \mathrm{HCl}$ and (b) $3 \cdot 5 \% \mathrm{NaCl}$.
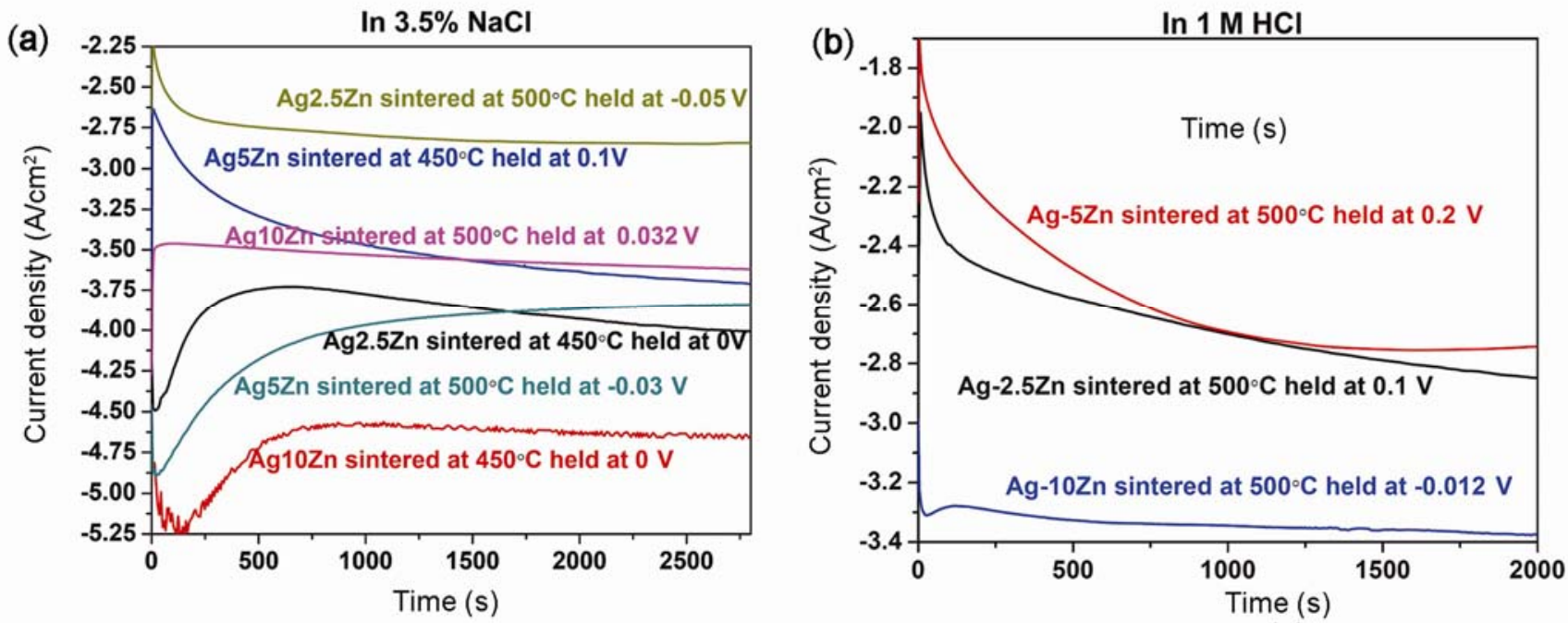

Figure 12. Potentiodynamic polarization (Tafel plot) of prematurely sintered Ag-Zn aggregates in (a) $1 \mathrm{M} \mathrm{HCl}$ and (b) $3 \cdot 5 \%$ $\mathrm{NaCl}$. Chronoamperometric curves of the sintered Ag-Zn aggregates in (a) $3.5 \% \mathrm{NaCl}$ and (b) $1 \mathrm{M}$ HCl held at the corresponding critical potentials for different compositions. 
Table 2. Critical potentials for different alloys obtained from potentiodynamic plots.

\begin{tabular}{|c|c|c|c|}
\hline Corrosive used & Sintering temperature $\left({ }^{\circ} \mathrm{C}\right)$ & Sample & Critical potentials (V) \\
\hline \multirow[t]{2}{*}{$1 \mathrm{M} \mathrm{HCl}$} & 450 & $\begin{array}{l}\text { Ag-2.5 wt } \% \text { Zn } \\
\text { Ag-5 wt\% Zn } \\
\text { Ag-10 wt } \% \text { Zn }\end{array}$ & $\begin{array}{l}0 \cdot 2 \\
0 \cdot 1 \\
0 \cdot 15\end{array}$ \\
\hline & 500 & $\begin{array}{l}\text { Ag-2.5 wt\% Zn } \\
\text { Ag-5 wt\% Zn } \\
\text { Ag-10 wt\% Zn }\end{array}$ & $\begin{array}{c}0 \cdot 1 \\
0 \cdot 2 \\
-0 \cdot 012\end{array}$ \\
\hline \multirow[t]{2}{*}{$3 \cdot 5 \% \mathrm{NaCl}$} & 450 & $\begin{array}{l}\text { Ag-2.5 wt } \% \mathrm{Zn} \\
\mathrm{Ag}-5 \mathrm{wt} \% \mathrm{Zn} \\
\mathrm{Ag}-10 \mathrm{wt} \% \mathrm{Zn}\end{array}$ & $\begin{array}{l}0 \\
0 \cdot 1 \\
0\end{array}$ \\
\hline & 500 & $\begin{array}{l}\text { Ag-2.5 wt } \% \text { Zn } \\
\text { Ag-5 wt } \% \text { Zn } \\
\text { Ag-10 wt } \% \text { Zn }\end{array}$ & $\begin{array}{l}-0.05 \\
-0.03 \\
0.035\end{array}$ \\
\hline
\end{tabular}
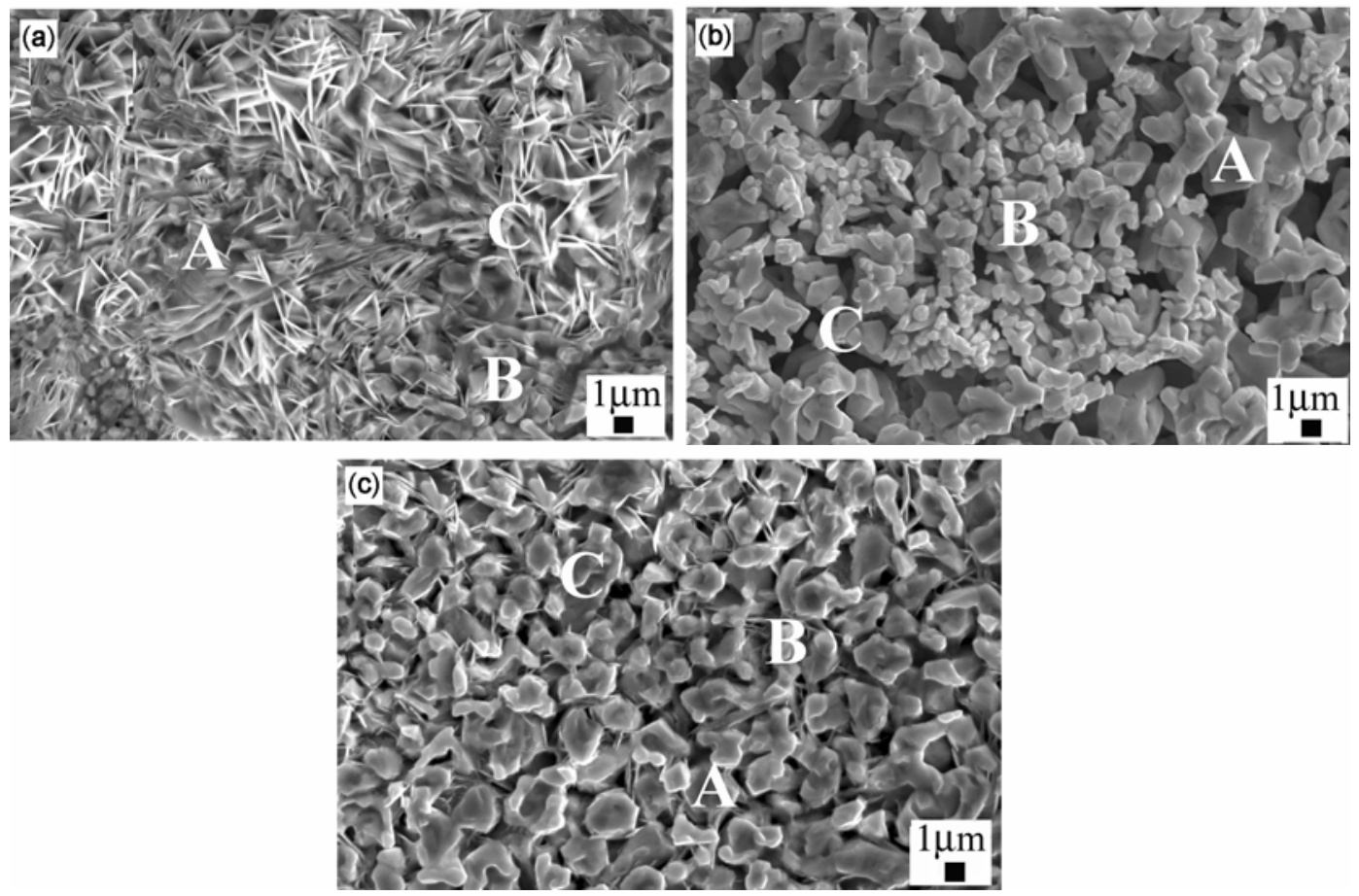

Figure 13. Scanning electron micrographs showing the microstructures of porous Ag through potentiostatically dealloying of the (a) Ag-2.5 wt\% $\mathrm{Zn}$, (b) Ag-5 wt\% Zn and (c) Ag-10 wt\% Zn samples sintered at $500{ }^{\circ} \mathrm{C}$ in $3.5 \% \mathrm{NaCl}$. Composition has been measured (using EDS) at the points marked A, B and $\mathrm{C}$ in the micrographs.

with respect to time for each of the samples are then plotted. It is observed that the onset of dealloying or dissolution of Zn has occurred very fast, and it is because, the chosen critical potential is quite above the stability range of $\mathrm{Zn}$ as observed in the Pourbaix diagram of $\mathrm{Zn}$ as shown in figure 10 . In $3.5 \% \mathrm{NaCl}$, initially there is a sudden drop in current density (shown in figure 12a) within few seconds and then, the current density is again increasing reaching to a threshold current. Then, it becomes stabilized suggesting that complete depletion of $\mathrm{Zn}$ has taken place. But in $1 \mathrm{M} \mathrm{HCl}$, the trend is quite different. The reason may be due to the enhanced acidic nature of
$1 \mathrm{M} \mathrm{HCl}$, which restricts the passivation on the $\mathrm{Ag}$ surface resulting into constant dissolution from both Ag and Zn components.

Figure 13(a)-(c) shows the scanning electron micrographs showing microstructures of surfaces of porous Ag templates after potentiostatic dealloying of the Ag2.5 wt $\% \mathrm{Zn}, \mathrm{Ag}-5 \mathrm{wt} \% \mathrm{Zn}$ and Ag-10 wt\% Zn aggregates sintered at $500{ }^{\circ} \mathrm{C}$ in $3.5 \% \mathrm{NaCl}$, respectively, at the respective critical potentials (table 2 ). EDS analysis has been done at the points marked on the microstructures, and are shown in table 3 . Fine pores are observed in some regions of the $\mathrm{Ag}-5 \mathrm{wt} \% \mathrm{Zn}$ sintered at $500{ }^{\circ} \mathrm{C}$. But the 
Table 3. Compositional analysis (EDS) of the points shown in the micrographs of potentiostatically dealloyed surfaces of Ag-Zn samples sintered at $500{ }^{\circ} \mathrm{C}$ in $3.5 \% \mathrm{NaCl}$ at the points marked in figure 13 .

\begin{tabular}{|c|c|c|c|c|c|c|c|}
\hline $\begin{array}{l}\text { Corrosive } \\
\text { used }\end{array}$ & $\begin{array}{l}\text { Sintering } \\
\text { temperature }\end{array}$ & Sample & Spectrum & $\mathrm{Ag}(w \mathrm{t} \%)$ & Zn (wt\%) & $\mathrm{O}(\mathrm{wt} \%)$ & $\begin{array}{l}\text { Avg. pore } \\
\text { size }(\mu \mathrm{m})\end{array}$ \\
\hline \multirow[t]{9}{*}{$3.5 \% \mathrm{NaCl}$} & \multirow[t]{9}{*}{$500{ }^{\circ} \mathrm{C}$} & $\mathrm{Ag}-2.5 \mathrm{wt} \% \mathrm{Zn}$ & A & $97 \cdot 13$ & $2 \cdot 01$ & $0 \cdot 87$ & \multirow[t]{3}{*}{$0 \cdot 98$} \\
\hline & & & B & $97 \cdot 80$ & 1.94 & $0 \cdot 26$ & \\
\hline & & Figure 13(a) & $\mathrm{C}$ & $97 \cdot 44$ & $2 \cdot 05$ & 0.51 & \\
\hline & & \multirow[t]{2}{*}{ Ag-5 wt\% Zn } & A & $99 \cdot 84$ & 0 & $0 \cdot 16$ & \multirow[t]{3}{*}{$1 \cdot 6$} \\
\hline & & & B & $99 \cdot 34$ & $0 \cdot 18$ & 0.48 & \\
\hline & & Figure 13(b) & $\mathrm{C}$ & $97 \cdot 58$ & 0 & $0 \cdot 42$ & \\
\hline & & \multirow[t]{2}{*}{ Ag-10 wt\% Zn } & A & $95 \cdot 68$ & $3 \cdot 43$ & $0 \cdot 89$ & \multirow[t]{3}{*}{0.86} \\
\hline & & & B & $93 \cdot 79$ & $5 \cdot 48$ & 0.73 & \\
\hline & & Figure 13(c) & $\mathrm{C}$ & $95 \cdot 52$ & $3 \cdot 92$ & $0 \cdot 56$ & \\
\hline
\end{tabular}

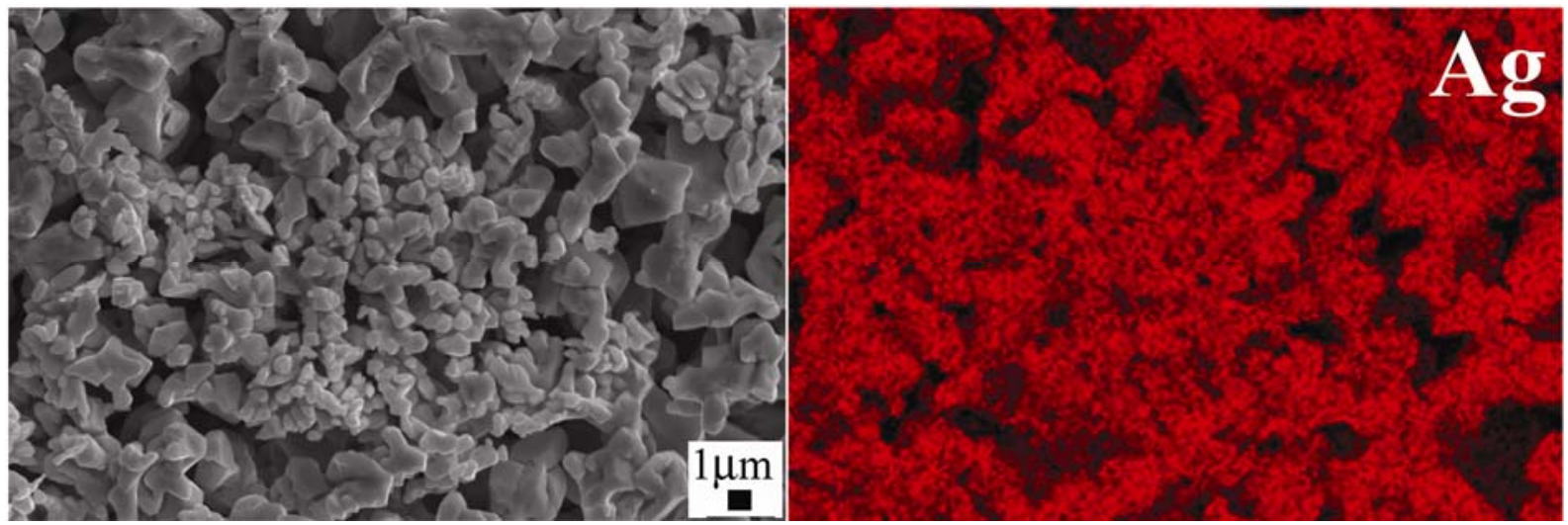

Figure 14. Mapping of the overall dealloyed surface area showing elemental distribution of $100 \%$ Ag after potentiostatically dealloying of the Ag-5 wt\% Zn sample sintered at $500{ }^{\circ} \mathrm{C}$ sample in $3 \cdot 5 \% \mathrm{NaCl}$.

size and distribution of the pores are found to be inhomogeneous. It may be attributed to the fact that the mechanism of dissolution might have changed continuously with further dissolution, and the electron cloud formed at the electrolyte metal interface might have restricted further dissolution. On the other hand, a star-shaped microstructure is observed in Ag-2.5 wt\% $\mathrm{Zn}$ sintered at $500{ }^{\circ} \mathrm{C}$. Upon EDS analysis, it is found that dissolution of $\mathrm{Zn}$ is very minute in $\mathrm{Ag}-2.5 \mathrm{wt} \% \mathrm{Zn}$ sintered at $500{ }^{\circ} \mathrm{C}$, and almost full $\mathrm{Zn}$ is retained at every point. Better results of dealloying are obtained in Ag-5 wt\% $\mathrm{Zn}$ and Ag-10 wt\% Zn sintered at $500{ }^{\circ} \mathrm{C}$. Upon comparison of all the micrographs at same magnification shown in figure 13(a)-(c), it is found that the microstructures after sintering have been retained with extensive dissolution of $\mathrm{Zn}$ in case of the aggregates Ag-5 wt\% $\mathrm{Zn}$ and $\mathrm{Ag}-$ $10 \mathrm{wt} \% \mathrm{Zn}$ sintered at $500{ }^{\circ} \mathrm{C}$ (table 3). Figure 14 shows the EDS elemental mapping of the $\mathrm{Ag}-5 \mathrm{wt} \% \mathrm{Zn}$ aggregate sintered at $500{ }^{\circ} \mathrm{C}$ after potentiostatic dealloying in $3.5 \% \mathrm{NaCl}$. No trace of $\mathrm{Zn}$ is found throughout the entire surface suggesting complete dezincification. Comparing table 4 and figure 14, it can be understood that the trace amount of $\mathrm{Zn}$ observed after doing point analysis (table 4) could be from the undersurface.
Figure 15(a)-(c) shows the scanning electron micrographs showing microstructures of surfaces of porous Ag templates after potentiostatic dealloying of the Ag-Zn sintered aggregates sintered at $450{ }^{\circ} \mathrm{C}$ in $3 \cdot 5 \% \mathrm{NaCl}$ at critical potentials as shown in table 2. EDS analysis has been done at the points marked on the microstructures, and are shown in table 4 . The morphologies of three sample surfaces are quite similar in pattern, and different from those of sintered samples at $500{ }^{\circ} \mathrm{C}$ shown in figure 13. In the present case, the re-deposition of Ag forms finer globules for the sample of highest $\mathrm{Zn}$ content (Ag-10 wt\% Zn). But the pore size is found to be the smallest for the Ag-2.5 wt\% $\mathrm{Zn}$ samples. The average pore size $(992 \mathrm{~nm})$ is found to be the largest in the Ag$5 \mathrm{wt} \% \mathrm{Zn}$ samples. From the EDS analysis at the points marked on the microstructure, it is found that almost complete dissolution of $\mathrm{Zn}$ has also occurred from the Ag-10 wt\% Zn sample. Since, the initial $\mathrm{Zn}$ content is already very low (2.5\%) in the Ag-2.5 wt\% Zn sample, it cannot be analysed properly that how much $\mathrm{Zn}$ has really dissolved into the electrolyte upon dealloying.

In low $\mathrm{pH}$ acidic solution, i.e. in $1 \mathrm{M} \mathrm{HCl}$, the morphology of the dealloyed surface is somewhat different. Scanning electron micrographs (figure 16(a)-(c)) show 
Table 4. Compositional analysis (EDS) of the points shown in the micrographs of potentiostatically dealloyed surfaces of Ag-Zn samples sintered at $450{ }^{\circ} \mathrm{C}$ in $3.5 \% \mathrm{NaCl}$ at the points marked in figure 15 .

\begin{tabular}{lcccccc}
\hline Corrosive used & Sintering temperature & Sample & Spectrum & Ag (wt\%) & Zn (wt\%) & O (wt\%) \\
\hline $3.5 \% \mathrm{NaCl}$ & $450{ }^{\circ} \mathrm{C}$ & Ag-2.5 wt\% Zn & A & 97.48 & 1.87 & 0.65 \\
& & B & 98.48 & 1.43 & 0.09 \\
& Figure 15(a) & C & 99.52 & 0.41 & 0.07 \\
& Ag-5 wt\% Zn & A & 99.56 & 0.28 & $0 \cdot 16$ \\
& & B & 99.78 & 0 & 0.22 \\
& Figure 15(b) & C & 98.89 & 0.16 & 0.95 \\
& Ag-10 wt\% Zn & A & 98.79 & 0.41 & 0.88 \\
& & B & 97.90 & 1.95 & 0.15 \\
\hline
\end{tabular}
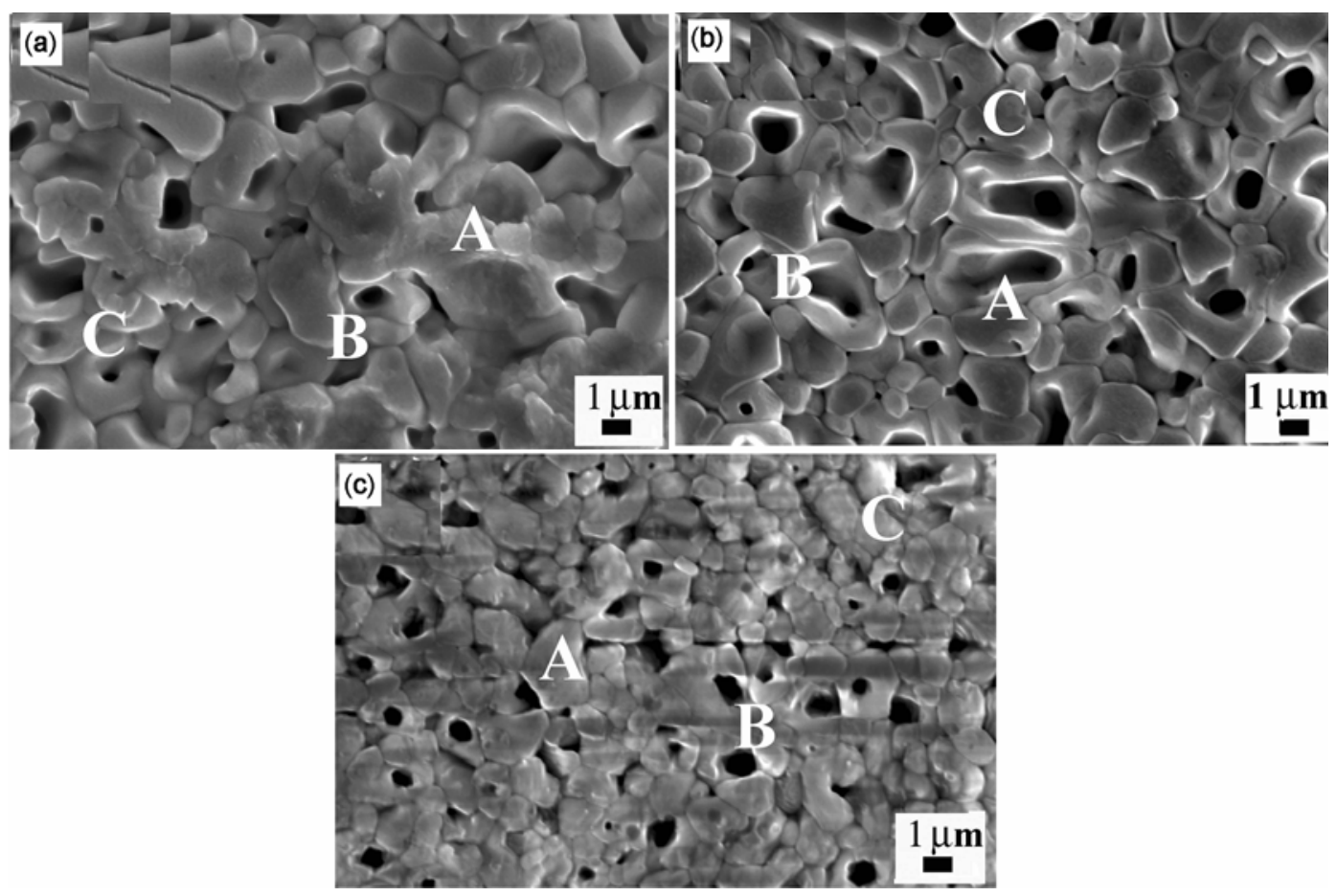

Figure 15. Scanning electron micrographs showing the microstructures of porous Ag through potentiostatically dealloying of the (a) Ag-2.5 wt\% Zn, (b) Ag-5 wt\% Zn and (c) Ag-10 wt\% Zn samples sintered at $450{ }^{\circ} \mathrm{C}$ in $3.5 \% \mathrm{NaCl}$. Composition has been measured (using EDS) at the points marked A, B and $\mathrm{C}$ in the micrographs.

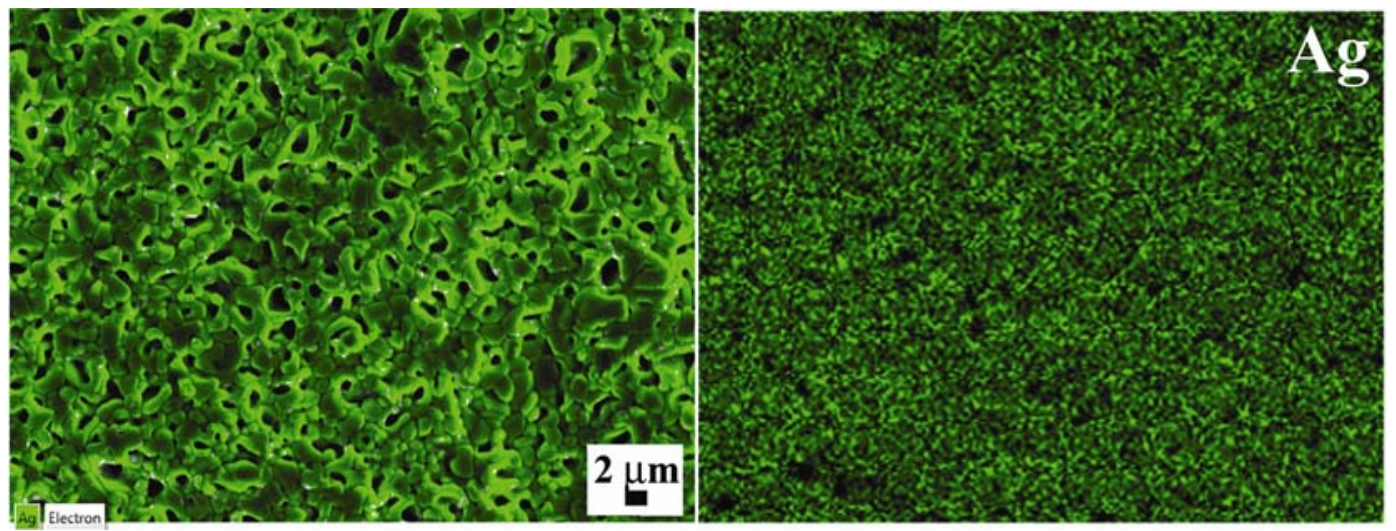

Figure 16. Mapping of the overall dealloyed surface area showing elemental distribution of $100 \% \mathrm{Ag}$ after potentiostatically dealloying of the $\mathrm{Ag}-5 \mathrm{wt} \% \mathrm{Zn}$ sample sintered at $500{ }^{\circ} \mathrm{C}$ in $1 \mathrm{M} \mathrm{HCl}$. 
Table 5. Compositional analysis (EDS) of the points shown in the micrographs of potentiostatically dealloyed surfaces of $\mathrm{Ag}-\mathrm{Zn}$ samples sintered at $500^{\circ} \mathrm{C}$ in $1 \mathrm{M} \mathrm{HCl}$ at the points marked in figure 17.

\begin{tabular}{|c|c|c|c|c|c|c|c|}
\hline $\begin{array}{l}\text { Corrosive } \\
\text { used }\end{array}$ & $\begin{array}{l}\text { Sintering } \\
\text { temperature }\end{array}$ & Sample & Spectrum & Ag (wt\%) & $\mathrm{Zn}(\mathrm{wt} \%)$ & $\mathrm{O}(\mathrm{wt} \%)$ & $\begin{array}{l}\text { Avg. pore } \\
\text { size }(\mu \mathrm{m})\end{array}$ \\
\hline \multirow[t]{9}{*}{$1 \mathrm{M} \mathrm{HCl}$} & \multirow[t]{9}{*}{$500^{\circ} \mathrm{C}$} & Ag-2.5 wt $\% \mathrm{Zn}$ & A & $98 \cdot 45$ & $0 \cdot 34$ & $1 \cdot 21$ & \multirow[t]{3}{*}{$4 \cdot 2$} \\
\hline & & & B & $97 \cdot 87$ & $1 \cdot 84$ & $0 \cdot 29$ & \\
\hline & & Figure 17(a) & $\mathrm{C}$ & $97 \cdot 53$ & $2 \cdot 11$ & $0 \cdot 36$ & \\
\hline & & \multirow[t]{2}{*}{ Ag-5 wt\% Zn } & A & $97 \cdot 85$ & $1 \cdot 52$ & 0.63 & \multirow[t]{3}{*}{$2 \cdot 6$} \\
\hline & & & B & $96 \cdot 42$ & $2 \cdot 78$ & $0 \cdot 8$ & \\
\hline & & Figure 17(b) & $\mathrm{C}$ & $97 \cdot 11$ & $1 \cdot 88$ & $1 \cdot 01$ & \\
\hline & & \multirow[t]{2}{*}{$\mathrm{Ag}-10 \mathrm{wt} \% \mathrm{Zn}$} & A & $95 \cdot 07$ & $3 \cdot 82$ & $1 \cdot 11$ & \multirow[t]{3}{*}{$1 \cdot 4$} \\
\hline & & & B & $96 \cdot 36$ & $3 \cdot 41$ & $0 \cdot 33$ & \\
\hline & & Figure 17(c) & C & $95 \cdot 79$ & $4 \cdot 08$ & $0 \cdot 13$ & \\
\hline
\end{tabular}
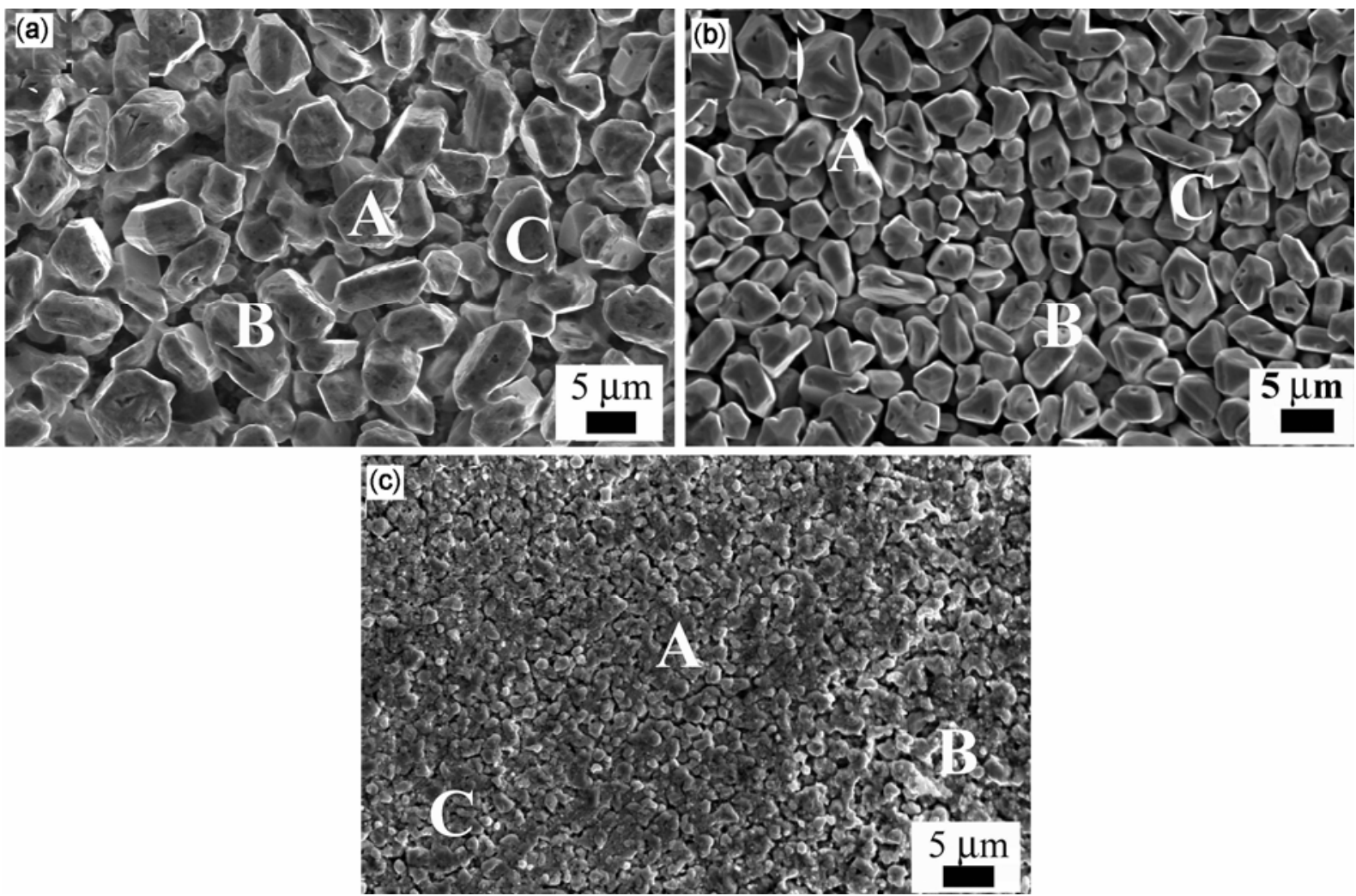

Figure 17. Scanning electron micrographs showing the microstructures of porous Ag through potentiostatically dealloying of the (a) Ag-2.5 wt\% Zn, (b) Ag-5 wt\% Zn and (c) Ag-10 wt\% Zn samples sintered at $500{ }^{\circ} \mathrm{C}$ in $1 \mathrm{M} \mathrm{HCl}$. Composition has been measured (using EDS) at the points marked A, B and C in the micrographs.

microstructures of the surfaces of porous Ag templates after potentiostatic dealloying of the Ag-2.5 wt\% Zn, Ag-5 wt\% Zn and Ag-10 wt\% Zn aggregates sintered at $500{ }^{\circ} \mathrm{C}$ in $1 \mathrm{M} \mathrm{HCl}$, respectively, at critical potentials (table 2). EDS analysis has been done at the points marked on the microstructures, and is shown in table 5. Discrete particles of Ag are re-deposited back on the matrix after dissolution. Thus, the mechanical integrity of the sample may be lost if the whole sample would have been exposed to the electrolyte for potentiostatic dealloying. This effect is most visible in the Ag-2.5 wt $\%$ Zn sample. It is also very clear from figure 10 that there could be possibility of $\mathrm{AgCl}$ formation which would lead to complete dissolution of the sample. Particle sizes are found to be smallest for the Ag-10 wt\% Zn sample. The composition at the points (marked in figure 16(a)-(c)) shows that some amount of $\mathrm{Zn}$ is retained in the particles and the composition profile follows a similar pattern in all the samples. Figure 17 shows the EDS elemental mapping of the Ag-5 wt\% $\mathrm{Zn}$ aggregate sintered at 
$500{ }^{\circ} \mathrm{C}$ after potentiostatic dealloying in $1 \mathrm{M} \mathrm{HCl}$. No trace of $\mathrm{Zn}$ is found throughout the entire surface suggesting complete dezincification. It also suggests that the trace amount of $\mathrm{Zn}$ observed after point analysis (table 5) is from the subsurface of the sample.

Figure 18 shows the SEM microstructure of porous Ag template obtained through potentiostatic dealloying of the Ag-10 wt $\% \mathrm{Zn}$ sintered at $500{ }^{\circ} \mathrm{C}$ at $0.36 \mathrm{~V}$ vs SCE in $3.5 \% \mathrm{NaCl}$ solution. Homogeneous very fine pores, the size ranging from 200 to $900 \mathrm{~nm}$ with an average pore size of $450 \mathrm{~nm}$, are found over the entire region of the matrix. When the holding potential is reduced to $0.32 \mathrm{~V}$, the microstructure obtained is much sharper with crystals of Ag being visible at higher magnification (shown in the inset). The corresponding SEM microstructure of porous

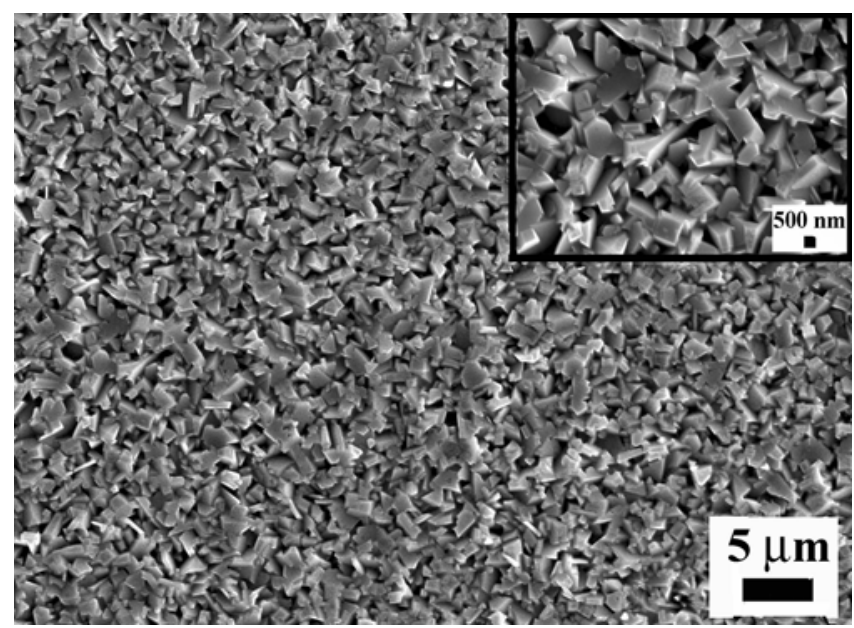

Figure 18. Scanning electron micrographs showing the microstructures of porous Ag template obtained through potentiostatically dealloying of the Ag-10 wt\% Zn sample sintered at $500{ }^{\circ} \mathrm{C}$ at $0.36 \mathrm{~V}$ vs SCE in $3.5 \% \mathrm{NaCl}$ solution. Inset shows a higher magnification image.

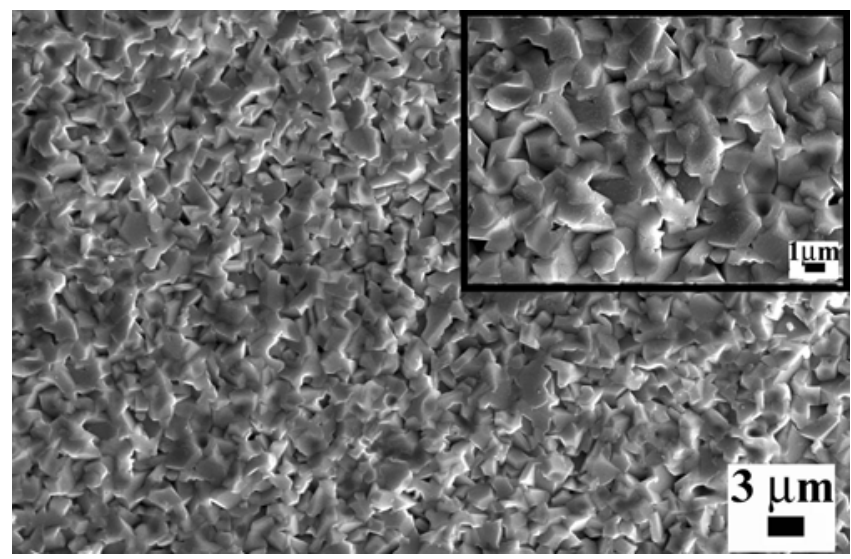

Figure 19. Scanning electron micrographs showing the microstructures of porous Ag template obtained through potentiostatically dealloying of the $\mathrm{Ag}-10 \mathrm{wt} \% \mathrm{Zn}$ sample sintered at $450{ }^{\circ} \mathrm{C}$ at $0.32 \mathrm{~V}$ vs SCE in $3.5 \% \mathrm{NaCl}$ solution. Inset shows a higher magnification image.
Ag template obtained through potentiostatic dealloying of the Ag-10 wt\% Zn sintered at $500{ }^{\circ} \mathrm{C}$ at $0.32 \mathrm{~V}$ vs SCE in $3 \cdot 5 \% \mathrm{NaCl}$ solution is shown in figure 19 . The EDS results (shown in figure 20) of the corresponding structure demonstrate that $\mathrm{Zn}$ has completely been leached out during potentiostatic dealloying from the sample Ag-10 wt\% Zn sintered at $500{ }^{\circ} \mathrm{C}$ at $0.36 \mathrm{~V}$ vs SCE in $3.5 \% \mathrm{NaCl}$ solution.

Thus, it is observed that potentiostatic dealloying is most effective in neutral $3 \cdot 5 \% \mathrm{NaCl}$ solution, and with increasing $\mathrm{Zn}$ content in solid solution range of phase diagram. The amount of dissolution is very high too. The actual mechanism of dissolution is not clear in immersion test. It is not clear whether selective dissolution of $\mathrm{Zn}$ has occurred, or dissolution-redeposition mechanism is active. On the other hand, since the holding potentials in the potentiostatic experiment lie always within the stability range of elemental $\mathrm{Ag}$ and quite above the stability range of $\mathrm{Zn}$, it may be concluded that full dealloying of $\mathrm{Zn}$ from the matrix (confirmed from EDS mapping) has
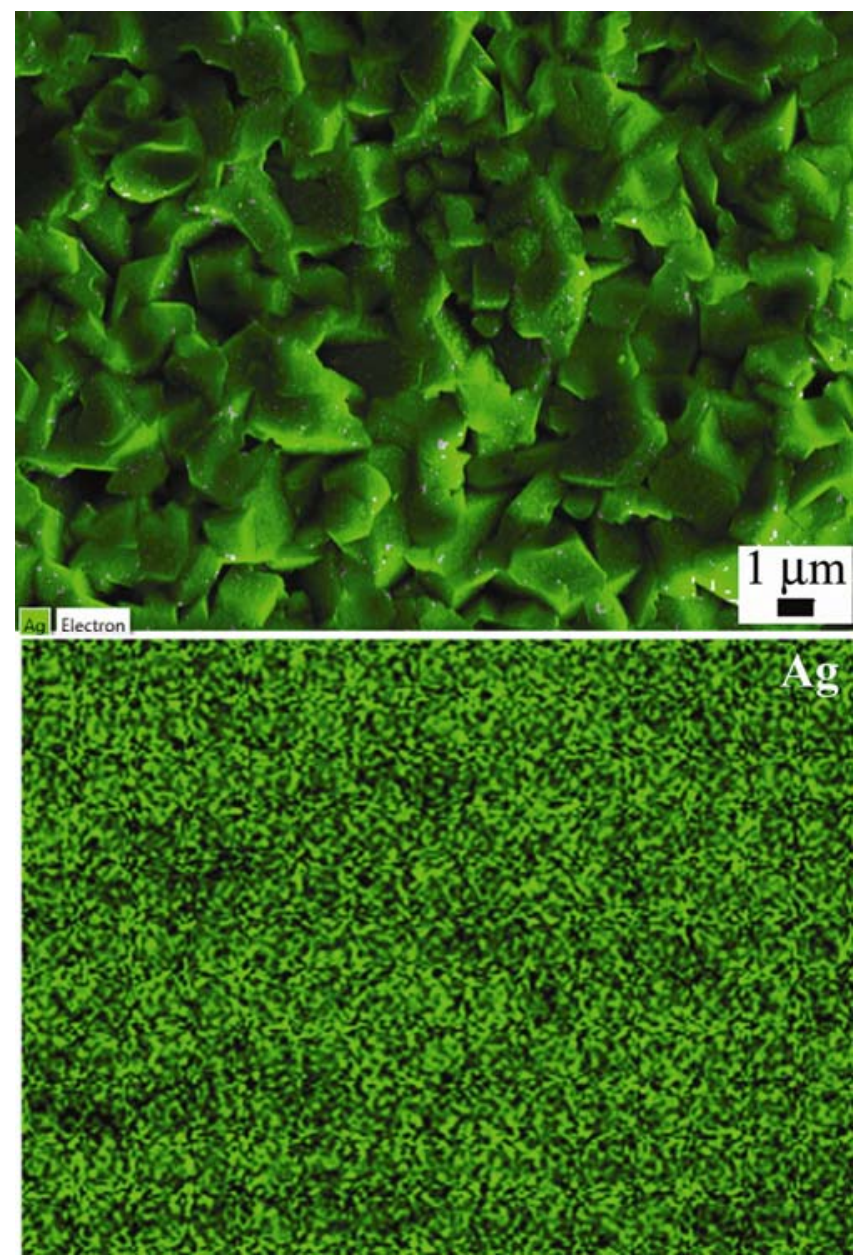

Figure 20. Mapping of the dealloyed surface of Ag showing elemental distribution of $\mathrm{Ag}$ over the entire area obtained through potentiostatically dealloying of the $\mathrm{Ag}-10 \mathrm{wt} \% \mathrm{Zn}$ sample sintered at $450{ }^{\circ} \mathrm{C}$ at $0.36 \mathrm{~V}$ vs SCE in $3.5 \% \mathrm{NaCl}$ solution. 
probably occurred following selective dissolution route. Moreover, the time taken is very less (only less than $3600 \mathrm{~s}$ ). Further, less than $500 \mathrm{~nm}$ pores are obtained (figures 18 and 19), which are distributed homogenously throughout the matrix in Ag-10 wt\% Zn sintered at $500{ }^{\circ} \mathrm{C}$ in $3.5 \% \mathrm{NaCl}$. Even in immersion test, best dissolution of $\mathrm{Zn}$ has been obtained for Ag-10 wt\% Zn samples in 3.5\% $\mathrm{NaCl}$ (figure 13). Thus, neutral electrolyte (3.5\% Zn) has proven to be better medium facilitating better dissolution than acidic solutions. Moreover, the present approach of partial sintering is considered because it has resulted in the formation of hard intermetallics at the Ag-Zn interfaces forming a network-like structure on one hand, and the presence of elemental Ag and $\mathrm{Zn}$ has facilitated selective leaching of the more active element ( $\mathrm{Zn}$ in the present case) forming a network of porous Ag structure.

\section{Conclusions}

Fabrication of nanoporous Ag templates from partiallysintered Ag-Zn alloys, respectively, using dealloying or selective dissolution mechanism is successful. Lowenergy ball milling for shorter time has prevented extensive alloying, and formation of intermetallic compounds. Partial sintering has also led to intermetallic compounds, preferably at the interface between $\mathrm{Zn}$ and Ag particles. Immersion tests have resulted into formation of pores, but these pores are inhomogeneous in size as well as in distribution. The $3.5 \% \mathrm{NaCl}$ solution has contributed to better porosity with the level of inhomogeneity less than that in $1 \mathrm{M} \mathrm{HCl}$. Moreover, for successful dealloying and formation of porous structures, higher Zn content is helpful. Chrono-amperometry tests have resulted into fine porous homogeneous microstructure with complete retention of the more noble metal Ag and complete dissolution of the active metal $\mathrm{Zn}$.

\section{References}

Attard G S, Bartlett P N, Coleman N R B, Elliott J M, Owen J $\mathrm{R}$ and Wang J H 1997 Science 278838

Balluffi R W and Cahn J W 1981 Acta Metall. 29493

Banhart J 2001 Prog. Mater. Sci. 46559

Bartlett P N, Gollas B, Guerin S and Marwan J 2002 Phys. Chem. Chem. Phys. 43835

Bond G C and Thompson D T 1999 Catal. Rev. Sci. Eng. 41 319

Chen Q and Sieradzki K 2013 J. Electrochem. Soc. 160 C226
Cherevko S, Xing X and Chung C 2010 Electrochem. Commun. 12467

Deakin J, Dong Z, Lynch B and Newman R C 2004 Corros. Sci. 462117

Ding Y and Erlebacher J D 2003 J. Amer. Chem. Soc. 1257772

Erlebacher J D, Aziz M J, Karma A, Dimitrov N and Sieradzki K 2001 Nature 410450

Fritz J D and Pickering H W 1991 J. Electrochem. Soc. 138 3209

Forty A J 1979 Nature 282597

Hayes J, Hodge A, Biener J, Hamza A V and Sieradzki K 2006 J. Mater. Res. 212611

Huang J F and Sun I W 2004 Chem. Mater. 161829

Jia F L, Yu C F, Ai Z H and Zhang L Z 2007 Chem. Mater. 19 3648

Joo S H, Choi S J, Oh I, Kwak J, Liu Z, Terasaki O and Ryoo R 2001 Nature 412169

Katagiri A and Nakata M 2003 J. Electrochem. Soc. 150 C585

Li R and Sieradzki K 1992 Phys. Rev. Lett. 681168

Mandal M, Singh D, Gouthama, Murty B S, Sangal S and Mondal K 2014 Bull. Mater. Sci. 37743

Massalski T B 1986 Binary alloy phase diagram (OH, Metals Park: American Society for Metals)

Moffat T P, Fan F R and Bard A J 1991 J. Electrochem. Soc. 1383224

Nakajima H, Hyun S K, Ohashi K, Ota K and Murakami K 2001 Colloidal Surf A: Physicochem. Eng. Aspects 179209

Newman R C, Meng F T and Sieradzki K 1988 Corros. Sci. 28 523

Pavlik A and Adkins H 1946 J. Am. Chem. Soc. 681471

Pickering H W and Wagner C 1967 J. Electrochem. Soc. 114 698

Pourbaix M 1966 Atlas of electrochemical equilibria in aqueous solutions (New York: Pergamon)

Pugh D V, Dursun A and Corcoran S G 2005 J. Electrochem. Soc. 152 B455

Qiu H, Zhang Z, Huang X and Qu Y 2011 Chem. Phys. Chem. 122118

Rintoul M D, Torquato S, Yeong C, Keane D T, Erramilli S, Jun Y N, Dabbs D M and Akshay I A 1996 Phys. Rev. 54 2663

Shapovalov V 1994 MRS Bull. 1924

Sieradzki K and Newman R C 1986 J. Electrochem. Soc. 133 1979

Velev O D and Kaler E W 2000 Adv. Mater. 12531

Wada T, Setyawan A D, Yubuta K and Kato H 2011 Scr. Mater. 65532

Yeh F H, Tai C C, Huang J F and Sun I W 2006 J. Phys. Chem. B110 5215

You T Y, Niwa O, Tomita M and Hirono S 2003 Anal. Chem. 752080

Zhang C, Sun J, Xu J, Wang X, Ji H, Zhao C and Zhang Z 2012 Electrochim. Acta 63302 